\title{
A novel phenomenological model for dynamic behavior of magnetorheological elastomers in tension- compression mode
}

\author{
Hossein Vatandoost ${ }^{1}$, Mahmood Norouzi ${ }^{1}$, Mohammad Mohsen Shahmardan ${ }^{1}$, Seyed Masoud Sajjadi \\ Alehashem $^{2}$, Yi Qing Ni ${ }^{3}$, and Stoyan K. Smoukov ${ }^{4}$ \\ ' Department of Mechanical Engineering, Shahrood University of Technology, Shahrood, Iran. \\ ${ }^{2}$ Department of Civil Engineering, Kharazmi University, Karaj Campus, Iran. \\ ${ }^{3}$ Department of Civil and Environmental Engineering, The Hong Kong Polytechnic \\ University, Hung Hom, Kowloon, Hong Kong, China. \\ ${ }^{4}$ Department of Materials Science and Metallurgy, University of Cambridge, 27 Charles \\ Babbage Road, Cambridge CB3 OFS, UK.
}

Email: sks46@cam.ac.uk 


\begin{abstract}
Tension-compression operation in MR elastomers (MREs) offers both the most compact design and superior stiffness in many vertical load-bearing applications such as MRE bearing isolators in bridges and buildings, suspension systems and engine mounts in cars, and vibration control equipment. It suffers, however, from lack of good computational models to predict device performance, and as a result shear-mode MREs are widely used in the industry, despite their low stiffness and load-bearing capacity. We start with a comprehensive review of MREs modeling and their dynamic characteristics, showing previous studies have mostly focused on dynamic behavior of MRE in the shear mode, though the MRE strength and MR effect are greatly decreased at high strain amplitudes, due to increasing distance between the magnetic particles. Moreover, the characteristic parameters of the current models either frequency, strain or magnetic field are constant; hence, new model parameters must be recalculated for new loading conditions. This is an experimentally time consuming and computationally expensive task, and no models capture the full dynamic behavior of the MREs at all loading conditions. In this study, we present an experimental setup to test MREs in a coupled tension-compression mode, as well as a novel phenomenological model which fully predicts the stress-strain behavior of the as a function of magnetic flux density, loading frequency and strain. We use a training set of experiments to find the experimentally derived model parameters, which can predict by interpolation the MRE behavior in the relatively large continuous range of frequency, strain and magnetic field. We also challenge the model to make extrapolating predictions and compare to additional experiments outside the training experimental data set with good agreement. Further development of this model would allow design and control of engineering structures equipped with tension-compression MREs and all the advantages they offer.
\end{abstract}




\section{1}

\section{Introduction}

Literature review

\subsection{Literature review}

Magnetorheological (MR) elastomers (MREs) are a class of responsive materials with numerous applications. Research in MR materials was initiated by Jacob Rabinow in 1948 focusing on magnetorheological fluids (MRFs) [1]. MR fluids have a widespread use in mitigating vibration [25]and have been used in semi-active damping devices [6-8], particularly dampers in buildings [5, 915], bridges and suspension systems [16-20], shock absorbers [21-23], rotary actuators [24], clutches and brakes [1, 25-30].

Responding to needs for load bearing, faster responses, and compact tension actuators, magnetorheological elastomers (MREs) were developed. They are used in many macroscopic (prosthetics [31], responsive vehicle seat suspensions [32-34], engine mounts [35, 36], adaptive tuned vibration absorbers (ATVAs) [37-45], smart variable stiffness and damping isolators (VSDIs) [46, 47], vibratory pile hammers [48], smart vehicle bumpers [49], noise barrier systems [50], MRE valve [51], and MRE bearings [52-55]) as well as in microscopic applications (variable impedance surfaces [56], micro cantilevers [57], smart composites [58-60], sensors [61-63], touch-screen panel [64], flexible controllable micro-pump [65, 66], magnetometers [67], and artificial lymphatic vessels [68]). They are especially suited to shifting the vibration of structures away from harmful resonance frequencies [69-71].

They are part of the wider class of magnetorheological (MR) materials, such as MR fluids, MR foams, MR gels, MR plastomers and MR elastomers - intelligent new materials whose rheological properties can be dynamically adjusted by applying an external magnetic field. MR materials are fabricated by embedding micron-sized magnetizable particles in non-magnetic matrices such as fluid, gel or rubber like materials. The tunable interaction between the particles allows the mechanical properties of the composite to vary, to be made stiffer with the applied magnetic field. These materials have fast response times (down to less than ten milliseconds) to changes in magnetic fields, which largely depend on the viscoelastic properties of the matrix [72-76]. 
The earliest, and most widespread class of magnetic responsive materials, magnetorheological fluids (MRFs) are colloidal suspensions of magnetizable particles whose viscosity can be enhanced greatly by applying external magnetic field. This results in the formation of magnetic particle structures that temporarily get locked in place, can result in a high yield stress, and enormous on/off changes in steady-state shear viscosity $[76,77]$. Solid analogues of MRFs - MR gels and elastomers exhibit a lower dynamic range but overcome some shortcomings of MRFs (sedimentation, need for a container vessel, leakage, relatively slow response) by suspending the particles in a solid but deformable matrix $[73,78,79]$.

Generally, MREs are fabricated by embedding the micron sized magnetic particles either homogeneously (Isotropic MREs) or curing within magnetic fields to form permanent chain-like columnar structures (Anisotropic MRE) in a non-magnetic matrix. Both isotropic and anisotropic MREs show a reversible change in modulus with the application of an external magnetic field. The anisotropic MR elastomers show a larger magnetorheological effect than the isotropic composites but the magnetic polarization of the particles at the manufacturing stage is required[80]. It was found that the stiffness and damping properties of anisotropic MREs depend on the mutual directions of load, applied magnetic field and the particles alignment in the composite [81].

Recently MR fluid-elastomers (MRFEs) devices have combined MRFs and MREs, to take advantage of the complementary timescales and strains possible with each material, and are used in a variety of devices such as helicopter lag dampers, MRFE mounts and MRFE isolators. The MRFEs have a damping capacity which is dependent on strain amplitude and field strength, and weakly dependent on the excitation frequency. Hence, they can be used as a vibration isolator for tuning vibration characteristics in a large frequency range [82-84].

MREs normally operate in the elastic, pre-yield regime and have fast response times of a few milliseconds because the particles are already locked in place in the solid-like matrix [72-75]. In MR fluids the particles need to rearrange in the presence of a magnetic field and typically operate in a post-yield continuous shear flow regime, a steady-state which takes time to achieve, but which allows high dissipation over very large strains $[73,85-88]$. The dissipation properties are field dependent and 
response times to an external magnetic field are usually less than ten millisecond(Research on Smart Materials: Application of ER and MR fluid in an Automotive Crash Energy Absorber). However, the overall response time in MR fluid devices is a function of electromagnetic parameters, the capabilities of the driving electronics, as well as the operating conditions [86].

The ability to control both the stiffness and damping of MREs, whether used in MRFEs or by themselves, has attracted considerable interest in recent years. MRE devices can protect against seismic hazards through reducing of displacement and acceleration response of structures and also by shifting the structural system response away from resonance. MREs are being successfully brought into the market for different applications where active electrical control can be used to tune their intelligent material properties $[69,89]$. MRE can also be controlled by active, passive or semi-active strategies, the latter preferred because they combine lower power consumption than active ones and higher flexibility than the passive ones [90].

Novel geometries are being tried in order to produce systems with better performance. Schubert and Harrison [91] investigated the MR effect of MRE in a static shear, compression and tension. They have showed that the highest MR effect of MRE is related to the tension mode. Popp et al [75] investigated the performance of two MRE absorbers, one working in shear and one in compression mode. They showed that the compression mode MRE absorber had a larger frequency shift range than the shear mode MRE absorber. Rubber-like materials can bear more loads in compression than in shear mode [92].Thus, instead of pushing the typical double lab shear MRE isolators beyond operational limits, a compression mode MRE isolator is a better choice for extending the frequency shift range of MRE absorbers. Moreover, when an external magnetic field is applied, the elongation of MRE is quite large which enables their potential use in sensors, actuators due to their special magnetostrictive properties [93].

One of the newest and least investigated geometries is using MREs in tension-compression mode; see Figure 1 . For many load bearing devices tension-compression actuation could lead to more compact MRE devices with lower energy consumption. 


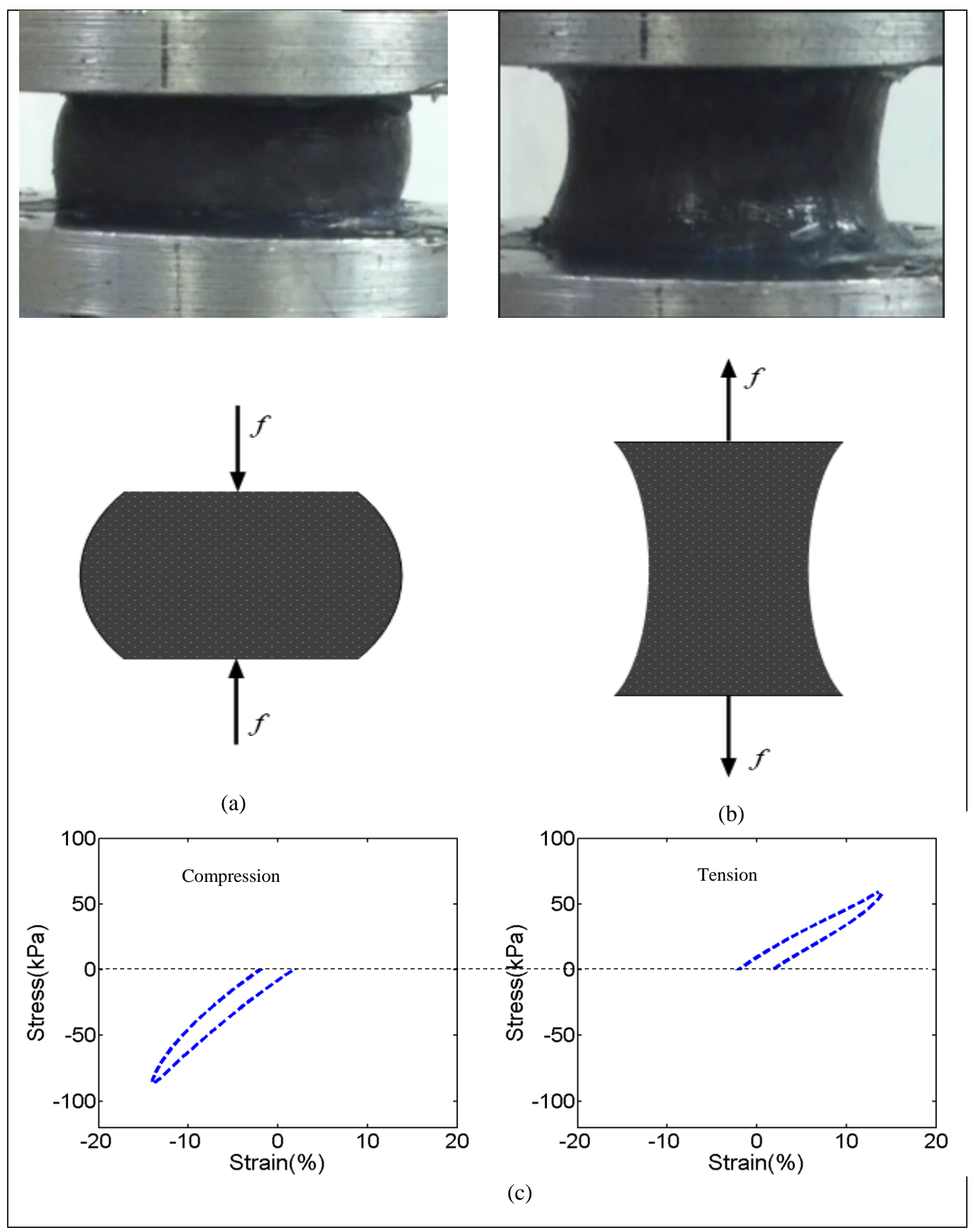

Figure 1. Diagram of deformed cylindrical MRE sample. (a) During compression (b) During tension (c) The typical stress-strain hysteresis curves in a dynamic tension-compression test.

Current models, however, hamper the design and implementation of such devices as they only capture the behavior of tension-compression actuation in very narrow ranges of operating conditions. 


\section{1}

A comprehensive dynamic model is needed to implement the appropriate integrated control system for real-time feedback, self-sensing, and identifying upcoming frequency characteristics of vibration sources. Here we present a model, with constant parameters obtainable from a few experiments, that captures the full shape of the stress-strain hysteresis curve over wide ranges of magnetic field, frequency and load parameters.

\subsection{Modeling Background}

On the other hand, the new generation of MR elastomer models have started to map the complex stress-strain relationship of MR elastomers to multiple excitation modes for better simulation and vibration control design $[72,84,94-105]$. Still, the previous dynamic models, such as the complex modulus model, cannot simultaneously describe well all separate aspects of the dynamic behavior of MREs, for instance, the nonlinear hysteresis, viscoelasticity in larger deformation, amplitude and frequency dependent characteristics. We overview the progress that has been done in different models for partial prediction of such properties. A linear differential equation for the stress-strain relationship of MR elastomers and then a fractional formula in frequency domain or complex modulus expression were presented with coefficients dependent on external magnetic fields [106, 107]. In those studies, MR elastomers were generally regarded as linear viscoelastic materials without the nonlinear hysteretic characteristics of MRE in large deformation.

MREs and MRE devices exhibit nonlinear hysteresis behavior, specifically in large amplitude excitation. This nonlinear hysteresis behavior typically is described by the Bouc-Wen model [108]. However, one of the main problems of the Bouc-Wen hysteresis model is estimating the values of its seven model parameters and specifically calculating the hysteretic variable that caused the parameter identification requiring great computational resources. Moreover, the parameters of the Bouc-Wen model in most of the former studies depend on input frequency, strain and other operating conditions [109-113]. Consequently, it is essential to run an optimization process for calculating the model's 
parameters at each different new loading conditions of strain, frequency and magnetic flux densities. This is not very useful for predicting behavior outside or inside of tested operating ranges. Based on the studies mentioned above, we can come to the conclusion that, the comprehensive model should consider all loading conditions such as input frequency, strain and magnetic field intensity in a continuous range in order to cover all dynamic performance of MRE.

In spite of the progress done with partial modeling of the system behavior, no comprehensive model exists to predict all the system characteristics. In the last two decades, additionally, researchers have mainly focused on the shear working mode of MRE and its applications [43, 94, 114-116]. In the case of shear working mode, where the direction of the applied magnetic field is perpendicular to the direction of loading, the MRE strength and MR effect are greatly decreased at high strain amplitudes, as they result in increasing distance between the magnetic particles.

In addition to shear mode, when compressive loading is applied in the direction of the magnetic field, the distance between the dipoles is reduced and the attractive interaction between the particles is facilitated, increasing the stiffness of the MRE at higher strains [117]. Generally, MRE in compression mode can be used for vertical load support, vertical vibration isolation and vertical shock absorber. Liao et al [92] assessed the magnetic-field-induced normal force of MRE under compression status. They have shown that the normal force increases with increasing magnetic field and precompression force. Liao et al [118] also presented a constitutive model consisting of hyperelasticity, viscoelasticity, and a magnetic part was proposed to describe the compressive property of MRE under high strain rate. Furthermore, Koo et al [119] developed a phenomenological model in order to capture the dynamic behavior of the MREs under compressive loadings. The coefficients of the parameters of this model are also frequency dependent and strain dependent.

Regarding tension mode, Bellan and Bossis [120] studied the effect of external magnetic field on viscoelastic properties of MRE such as elastic moduli under static and dynamic elongational test. They observed the change of $4 \mathrm{MPa}$ in dynamic storage modulus of MRE at low strains. Schubert and Harrison [121] studied dynamic behavior of MRE under tension test and found $74 \%$ relative MR 
effect when the particle alignment of anisotropic MREs was oriented parallel to an applied magnetic field of $67.5 \mathrm{mT}$.

Modeling of dynamic behavior of MRE in tension-compression mode has not been studied thoroughly. The dynamic behavior of MR elastomers in tension-compression deformation has recently been studied in terms of compressive stiffness and loss factors. It was found that when a magnetic field is applied both the compressive stiffness and loss factor values of aligned MREs were increased compared to the zero-field values $[122,123]$. In the mechanical systems, when the dynamic force is larger than the weight of the device, MREs will experience both tension and compression loading. Despite its mechanical advantages, comprehensive modelling of the tension-compression mode has been challenging due to its field-dependent non-linear hysteresis.

In most previous models for prediction the force-displacement or stress-strain behavior of MREs, however, the model's parameters were calculated at constant strain or constant frequency and these parameters will depend on strain or frequency in addition to magnetic flux density. Consequently, the predictive scope of the models is not very large, as it is essential to run an optimization process for calculating these parameters at each different new loading conditions of strain, frequency and magnetic flux densities. Based on the Table 1 the previous models of MRE and MRE devices are compared to the proposed model.

Table 1. Different models for predicting dynamic behavior of MRE and MRE devices.

\begin{tabular}{|c|c|c|c|c|c|}
\hline Reference & $\begin{array}{l}\text { Working } \\
\text { mode }\end{array}$ & $\begin{array}{l}\text { Range of } \\
\text { parameters }\end{array}$ & $\begin{array}{l}\text { Number of } \\
\text { parameters }\end{array}$ & Advantages & Disadvantages \\
\hline $\begin{array}{l}\text { Li et al } \\
{[124]}\end{array}$ & Shear & $\begin{array}{l}\text { Frequency }= \\
(1-10) \mathrm{Hz} \\
\text { Strain }=10 \% \\
\text { Magnetic field = } \\
(0-385) \mathrm{mT}\end{array}$ & Four & $\begin{array}{l}\text { Low number } \\
\text { of parameters }\end{array}$ & $\begin{array}{l}\text { Working in linear } \\
\text { regime. } \\
\text { Parameters will } \\
\text { change by the new } \\
\text { input strain. }\end{array}$ \\
\hline $\begin{array}{l}\text { Zhu et al } \\
{[125]}\end{array}$ & Shear & $\begin{array}{l}\text { Frequency }= \\
(1-10) \mathrm{Hz} \\
\text { Strain }=25 \% \\
\text { Magnetic field = } \\
(0-300) \mathrm{mT}\end{array}$ & Five & $\begin{array}{l}\text { Low number } \\
\text { of parameters }\end{array}$ & $\begin{array}{l}\text { Parameters will } \\
\text { change by the new } \\
\text { input strain. }\end{array}$ \\
\hline $\begin{array}{l}\text { Eem } \text { et al } \\
{[126]}\end{array}$ & Shear & $\begin{array}{l}\text { Frequency = } \\
(0.5-3) \mathrm{Hz}\end{array}$ & Five & $\begin{array}{l}\text { 1-Low } \\
\text { number of }\end{array}$ & $\begin{array}{l}\text { High } \\
\text { computational }\end{array}$ \\
\hline
\end{tabular}




\begin{tabular}{|c|c|c|c|c|c|}
\hline & & $\begin{array}{l}\text { Strain }=(5-26) \\
\% \\
\text { Magnetic field }= \\
(50-500) \mathrm{mT}\end{array}$ & & $\begin{array}{l}\text { parameters 2- } \\
\text { Constant } \\
\text { parameters }\end{array}$ & $\begin{array}{l}\text { expense for } \\
\text { calculating } \\
\text { parameters of } \\
\text { Ramberg-Osgood } \\
\text { model. }\end{array}$ \\
\hline $\begin{array}{l}\text { Yu et al } \\
{[109]}\end{array}$ & Shear & $\begin{array}{l}\text { Frequency = } \\
(0.1-4) \mathrm{Hz} \\
\text { Strain }=(8-32) \\
\% \\
\text { Current }=(0-3) \\
\text { amp }\end{array}$ & Five & $\begin{array}{l}\text { Low number } \\
\text { of parameters. }\end{array}$ & $\begin{array}{l}\text { Parameters } \\
\text { change by the new } \\
\text { input } \\
\text { frequency strain, } \\
\text { current. }\end{array}$ \\
\hline $\begin{array}{l}\text { Behrooz } \\
\text { et al }[110]\end{array}$ & Shear & $\begin{array}{l}\text { Frequency = } \\
0.1 \mathrm{~Hz} \\
\text { Strain = }(2-10) \\
\% \\
\text { Current }=(0-4) \\
\text { amp }\end{array}$ & Nine & & $\begin{array}{l}\text { 1-High } \\
\text { computational } \\
\text { expense } \\
\text { calculating } \\
\text { parameters of a } \\
\text { Bouc-wen element. } \\
\text { 2- Parameters will } \\
\text { change by the new } \\
\text { input strain and } \\
\text { frequency. }\end{array}$ \\
\hline $\begin{array}{l}\text { Yang et al } \\
{[127]}\end{array}$ & Shear & $\begin{array}{l}\text { Frequency = } \\
(0.1-4) \mathrm{Hz} \\
\text { Strain }=(8-32) \\
\% \\
\text { Current }=(0-3) \\
\text { amp }\end{array}$ & Ten & & $\begin{array}{l}\text { 1-High } \\
\text { computational } \\
\text { expense } \\
\text { calculating } \\
\text { parameters of a } \\
\text { Bouc-wen } \\
\text { equation. } \\
\text { 2-Parameters will } \\
\text { change by the new } \\
\text { input strain and } \\
\text { frequency. }\end{array}$ \\
\hline $\begin{array}{l}\text { Koo et al } \\
{[119]}\end{array}$ & Compression & $\begin{array}{l}\text { Frequency }= \\
(0.1-1) \mathrm{Hz} \\
\text { Strain }=5 \% \\
\text { Magnetic field = } \\
(0-600) \mathrm{mT}\end{array}$ & $\operatorname{six}$ & & $\begin{array}{l}\text { Parameters will } \\
\text { change by the new } \\
\text { input strain and } \\
\text { frequency. }\end{array}$ \\
\hline $\begin{array}{l}\text { Current } \\
\text { model }\end{array}$ & $\begin{array}{l}\text { Tension- } \\
\text { compression }\end{array}$ & $\begin{array}{l}\text { Frequency }= \\
(0.5-8) \mathrm{Hz} \\
\text { Strain }=(2-14) \\
\% \\
\text { Magnetic field = } \\
(0-260) \mathrm{mT}\end{array}$ & Ten & $\begin{array}{l}\text { Parameters } \\
\text { will not } \\
\text { change by the } \\
\text { new input } \\
\text { strain, } \\
\text { frequency and } \\
\text { magnetic } \\
\text { field. }\end{array}$ & $\begin{array}{l}\text { It is necessary to } \\
\text { carry out some } \\
\text { experiments to } \\
\text { determine the } 10 \\
\text { parameters, some } \\
\text { of which are not } \\
\text { commonly } \\
\text { measured. }\end{array}$ \\
\hline
\end{tabular}

In this paper, we introduce a model that resolves the complexity and shortcomings of previous attempts to describe the dynamic behavior of an MRE in tension-compression mode. Experimental oscillation tests are performed to obtain dynamic stress-strain hysteresis loops for several loading frequencies, displacement amplitudes and magnetic flux density. The results are fitted to a novel phenomenological model. The proposed model effectively captures the viscoelastic features, symmetric and asymmetric hysteretic characteristics, as well as their amplitude and frequency dependent behavior. The model's parameters are obtained through a least squares fit to the training set 
of experimental results. A visual illustration is provided to show the effects of parameters on the shape of stress-strain curves of the proposed model. In addition to interpolation, we also show the model is capable of extrapolation prediction which we match successfully with test experiments performed outside the previous parameter range.

\section{Experimental Methods}

\subsection{Test Setup}

The tension-compression test setup (Figure 2(a)) consists of a servo-hydraulic material testing machine (MTS-810) and uses two similar fixtures is designed to apply magnetic fields to the MRE sample using permanent magnets (Figure 2(b)). Each fixture has two parts fixed together by using four stainless steel screws, and flat permanent magnets can be sandwiched in between them and magnetic flux density can be changed easily by adding or removing permanent magnets. The upper part that is made of non-magnetic stainless steel in order to isolate the testing machine from the permanent magnets below it. The lower part is made of steel (St37) so the magnetic flux can pass through the plate be concentrated on the MRE that is fixed between the two fixtures (Figure 2(b)). Eight magnets with dimensions $50 \times 50 \times 12 \mathrm{~mm}$ were used. By changing the numbers of permanent magnets, the intensity of magnetic field that passes uniformly through the MRE is altered and flux densities from $\mathrm{B}=0 \mathrm{mT}$ (no magnet installed) to $\mathrm{B}=100,170,220$ and $260 \mathrm{mT}$ were achieved. $\mathrm{By}$ using this setup, a tension-compression tests of varying the magnetic flux density, displacement amplitude and motion frequency can be performed.

\subsection{Fabrication of the MRE sample}

The MRE specimen is an isotropic MRE, which contains carbonyl iron particles (type C3518, Sigma-Aldrich), silicone rubber (Silicone sealant, Selleys) and silicone oil (type 378364, SigmaAldrich). The iron particles (nominal diameter range from $3 \mu \mathrm{m}$ to $5 \mu \mathrm{m}$ ) are used as magnetic fillers and dispersed in the silicon matrix randomly. The two-components silicone rubber MRE specimen is 
fabricated using silicone rubber, silicone oil and carbonyl iron particles using weight fractions of $20 \%, 10 \%$, and $70 \%$ respectively. The silicone oil with a viscosity of 5 Pa.s was used to prevent particle agglomeration and to enhance their compatibility with the silicone compound. Besides, the common use of silicone oil as a diluting agent to decrease the modulus of silicone elastomers tends to enhance by facilitating frictional sliding at the interfaces between the matrix and the particles.

The iron particles were distributed thoroughly in a pre-weighed amount of the silicone oil, and the mixed liquid is blended further with the silicone rubber precursor. Then the isotropic mixture is poured into a cylinder mold and cured at room temperature $\left(23^{\circ} \mathrm{C}\right)$ for 24 hour, after which the MRE sample is ready to be tested. The tension-compression specimen we used was a small cylinder with a diameter of $40 \mathrm{~mm}$ and a height of $15 \mathrm{~mm}$ as shown in Figure 2(c). 


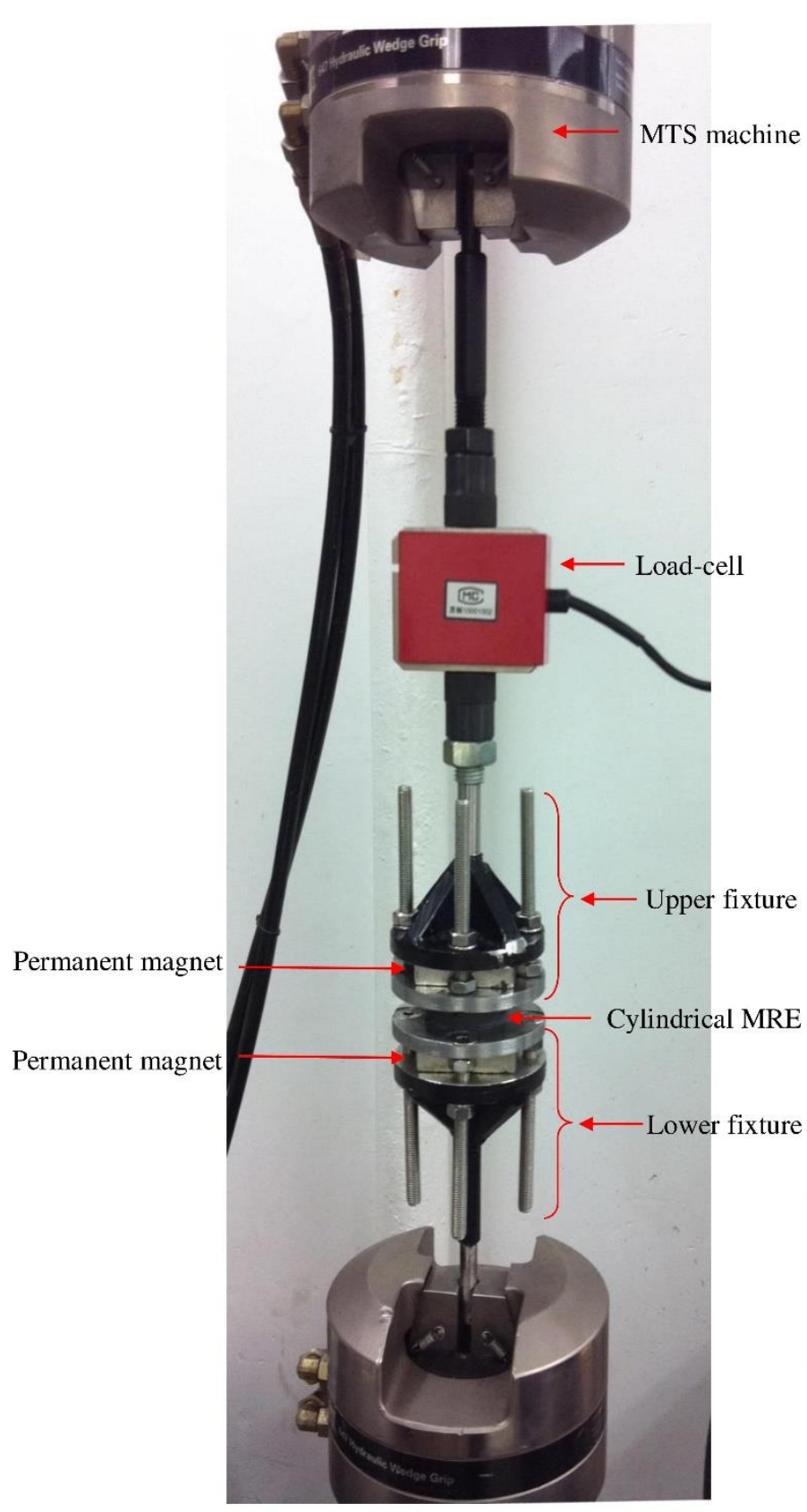

(a)

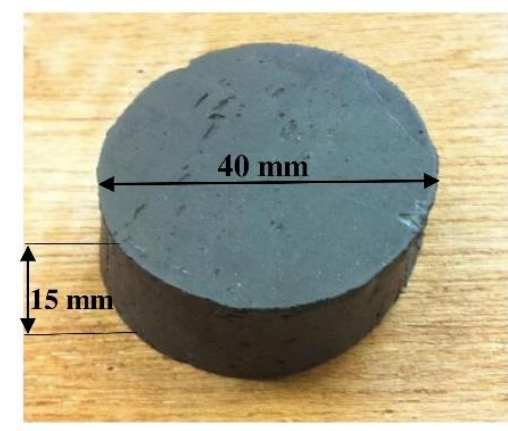

(c)

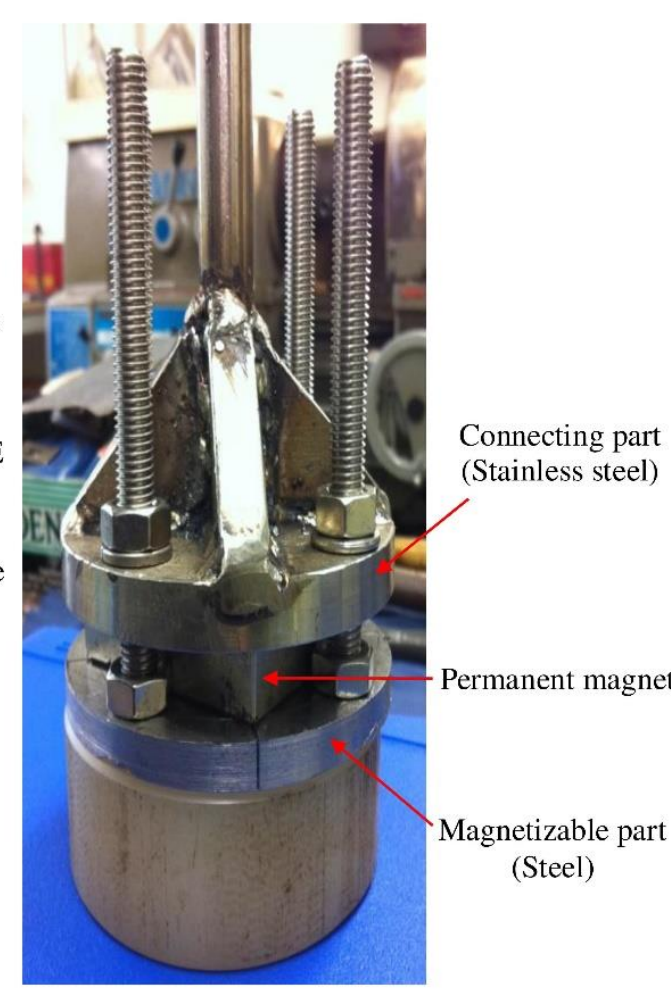

(b)

Figure 2. a) Experimental testing setup. b) Zoom of the cylindrical specimen of isotropic MRE, diameter = $40 \mathrm{~mm}$, height $=15 \mathrm{~mm}$. c) Zoom of top fixture with upper (connecting), lower (magnetizable) part and permanent magnet installed on it. 


\subsection{Testing procedure}

A series of tension-compression training set data tests were performed on MRE samples by varying the magnetic flux density, displacement amplitude and motion frequency. Magnetic flux densities varied from $\mathrm{B}=0 \mathrm{mT}$ (no magnet installed) to $\mathrm{B}=100,170,220$ and $260 \mathrm{mT}$. The MTS810 machine (Figure 2(a)) was used to apply a sinusoidal vertical displacement vs. time to the composite rubber MRE test sample.

The loading frequencies were $\mathrm{f}=0.5,1,3,5,8 \mathrm{~Hz}$ and the displacement amplitudes were $\mathrm{A}=$ $0.30,0.60,1.2$, and $2.1 \mathrm{~mm}$ that, for the specimens with $15 \mathrm{~mm}$ thickness, correspond to strains of $=2 \%, 4 \%, 8 \%, 14 \%$, respectively. Pre-compression deformation occurred for MREs upon increasing the magnetic field (by adding more permanent magnets). Then, the amplitudes adjusted according to new thickness of MRE after deformation somehow the strain rates were kept constant. The symmetric and asymmetric hysteresis shapes of stress-strain curves of tested MRE are obtained which are discussed in the next section.

\subsection{Supplementary testing}

By implementing the testing mentioning in the former section, dynamic behavior of MRE in tension-compression mode is investigated and model's parameters are obtained based on these experiments. Interpolating predictions can be made based on data within the existing range. To investigate model's performance further, we challenged the model to make extrapolating predictions outside the previous data range. We also performed corresponding supplementary tests and compared to the predicted model's response. The new experiments are done at frequency of $0.1 \mathrm{~Hz}$ and $0.3 \mathrm{~Hz}$ for strain sweep of $2 \%, 4 \%, 8 \%, 14 \%$, respectively, besides, at strain of $1 \%$ for frequency sweep of $0.1,0.3,0.5,1,3,5,8 \mathrm{~Hz}$. Magnetic flux densities, similarly, varied from $\mathrm{B}=0 \mathrm{mT}$ (no magnet installed) to $\mathrm{B}=100,170,220$ and $260 \mathrm{mT}$. We present the comparison of the extrapolating predictions from model parameters based on the training experimental data set which, as we show below, compare favorably to this extrapolating test data set. 


\section{Experimental results and Discussion}

\subsection{Hysteresis loops}

In several successive figures we will summarize the behavior of MREs in tension-compression mode for different field ranges, applied load amplitudes and frequency ranges. A typical hysteresis curve obtained at steady state in cyclic loading is shown in Figure 3. The experimental curves in Figure 4 through Figure 7 are examples of stable behavior of MRE under tension-compression oscillation. Under cyclic loading, the viscoelastic stress-strain response of MREs evolves over the first several cycles until a stable behavior is eventually obtained. This is observed in both filled and nonfilled rubber-like materials, and has been investigated intensively by Mullins and his co-workers and consequently is referred to as the "Mullins effect" [128]. Typical steady state hysteresis loops are nearly perfectly elliptical (referred to as linear behavior), or non-perfectly elliptical loops (nonlinear behavior) [129]. Two more parameters are used to characterize loops - area enclosed by the loop, and the angle between the origin and the point of maximum stress \& strain. For elliptical loops, the angle coincides with the slope of the major axis of the ellipse. 


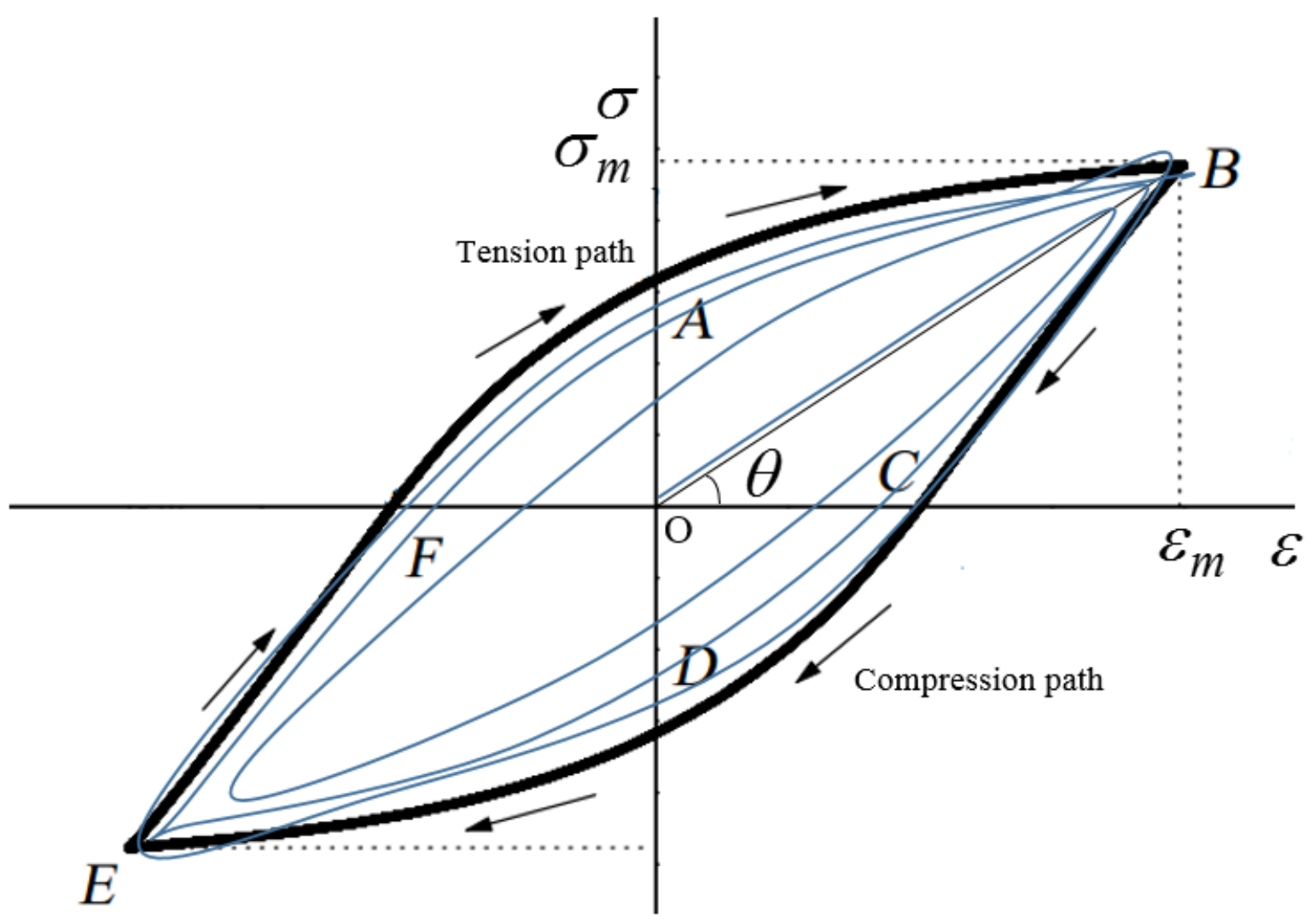

Figure 3. Diagram of a typical time-dependent hysteresis loop. Depending on the applied field and frequency, the shape and magnitude of the stress-strain curves in a cycle would change. Inside curves with red arrows show the transition from a non-actuated to a cyclic steady state (the Mullins effect). Outside dark line denotes the typical steady state, different for a particular set of cyclic forcing conditions (frequency, field, strain).

In dynamic applications, the viscoelastic properties of MREs play a substantial role. The energy within a perfectly elastic material is completely recovered when the stress is removed but the viscous contribution, which is caused by internal molecular friction, retards the elastic strain response and energy is lost. This lost energy is dissipated in the form of heat in the elastomer. The amount of energy lost per cycle of strain is known as 'hysteresis loss'.

Additionally, as seen in Figure 3 the non-zero stress $\left(\sigma_{A}\right.$ or $\left.\sigma_{D}\right)$ at zero strain $\left(\varepsilon_{O}\right)$ demonstrates the hysteresis effect. The area under the loading curve (EFAB) is proportional to the energy input and the area under the unloading curve (BCDE) is proportional to the energy returned. Accordingly, the difference area, which is enclosed between loading and unloading path, is the hysteresis loss or equivalent damping. Additionally, the slope of major axis of hysteresis loops $(\theta)$, the angle between the $\mathrm{x}$-axis and the line which is cross through origin $(0,0)$ and $\left(\varepsilon_{m}, \sigma_{m}\left(\varepsilon=\varepsilon_{m}\right)\right)$, 
(b)

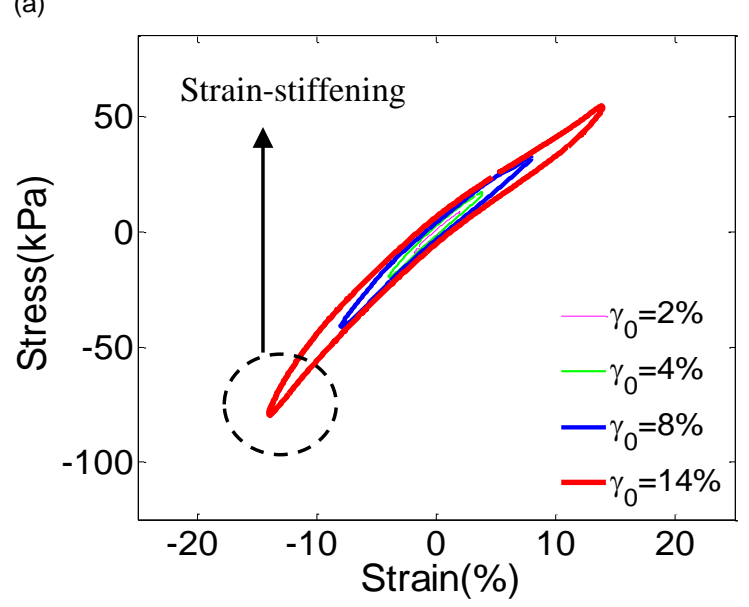

(c)

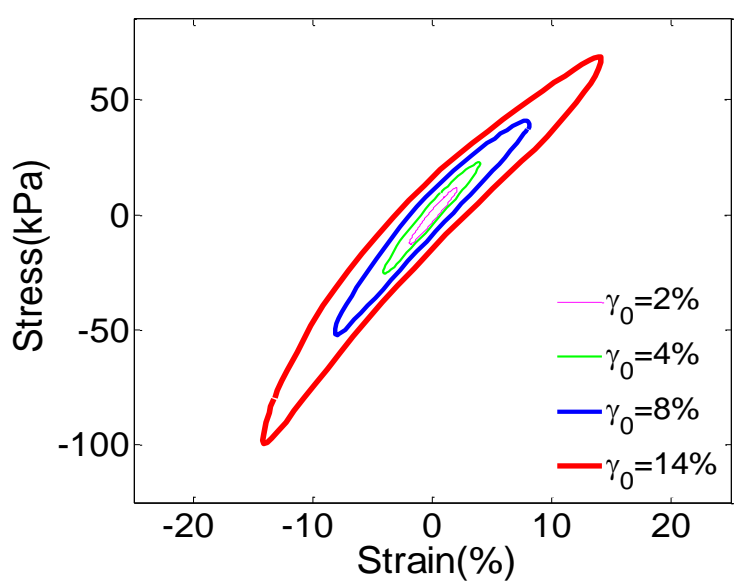

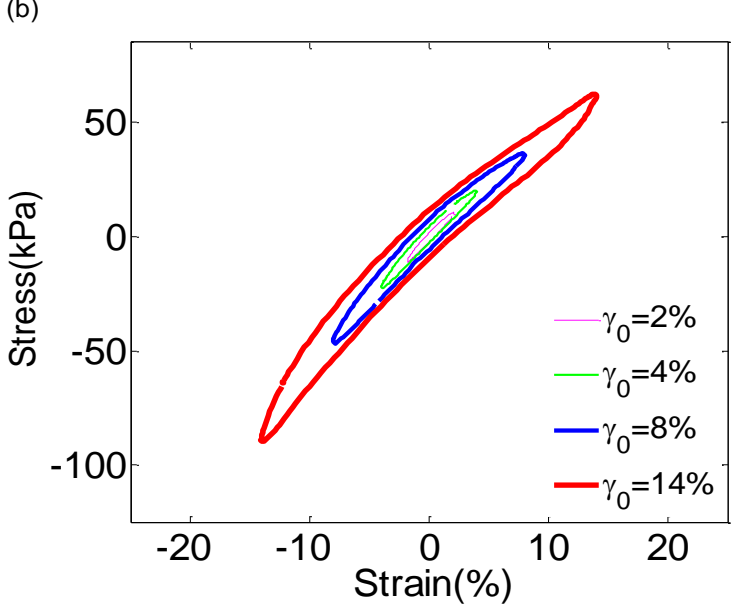

(d)

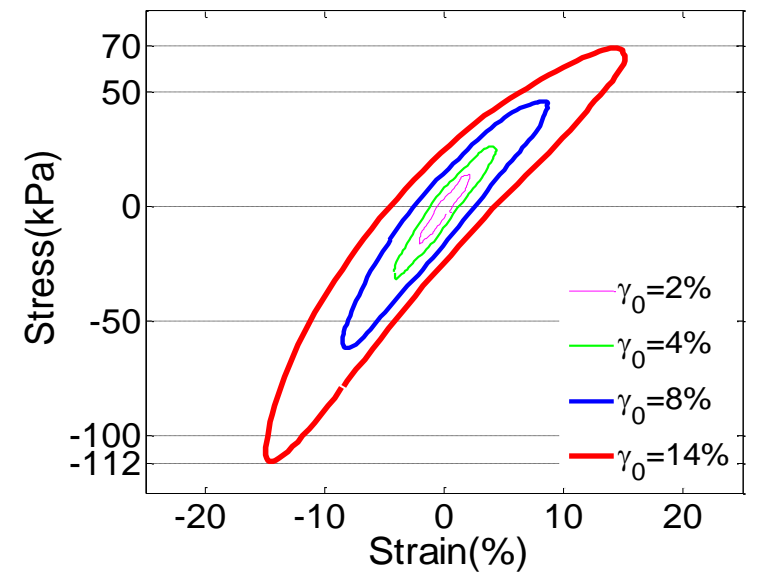

Figure 4. Hysteresis loops with magnetic flux density $B=0 \mathrm{mT}$ (without magnetic field). (a) $f=0.1 \mathrm{~Hz}$, (b) $f=1 \mathrm{~Hz}$, (c) $f=3 \mathrm{~Hz}$, (d) $f=8 \mathrm{~Hz}$.

Hysteresis loops of the MRE tested under different strains and frequencies are shown in Figure 4 and Figure 5 for magnetic flux density of $\mathrm{B}=0 \mathrm{mT}$ (without magnets) and $\mathrm{B}=272 \mathrm{mT}$ (with 4 magnets), respectively. These figures illustrate the effect of strain on the shape of the hysteresis loop for different input frequencies in the tension-compression oscillation. We see from both Figure 4 and Figure 5 that at low strains, such as $2 \%$ and $4 \%$, the shapes of the hysteresis curves are approximately symmetric with respect to the origin.

The figures show that MRE shows nonlinear asymmetric hysteresis behavior at higher strains, deviating from the elliptical shape in both situations with and without an applied magnetic field. At 
zero magnetic field, low frequency, and high strain, the MRE exhibits strain-stiffening, see the circled regions in Figure 4(a). Though symmetric looking here, the up-turn in tension and down-turn in compression are caused by slightly different mechanisms, and this leads to asymmetries under different conditions, as we'll see below.

(a)

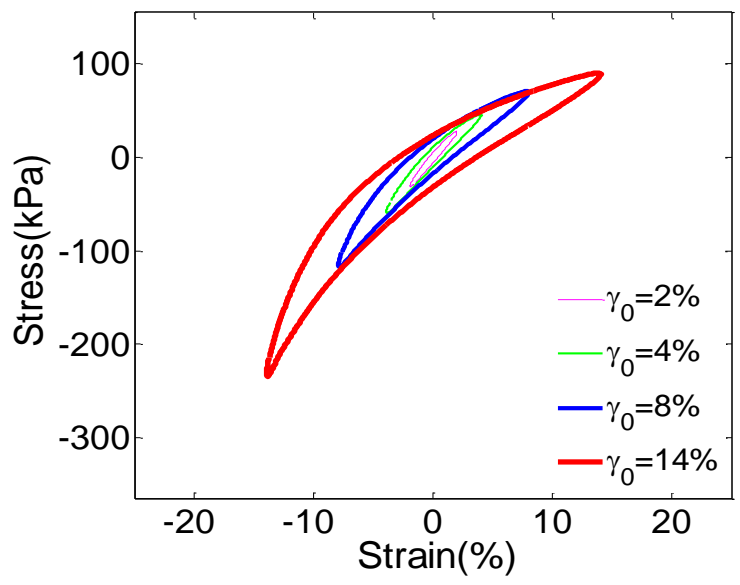

(c)

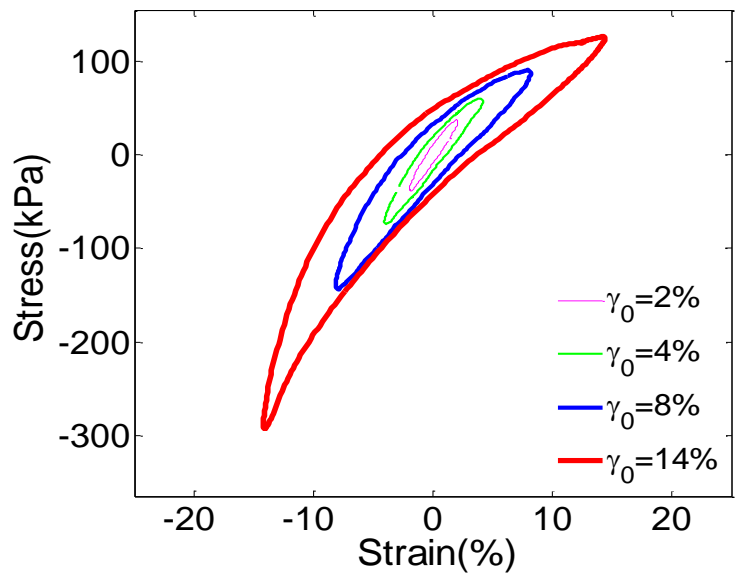

(b)

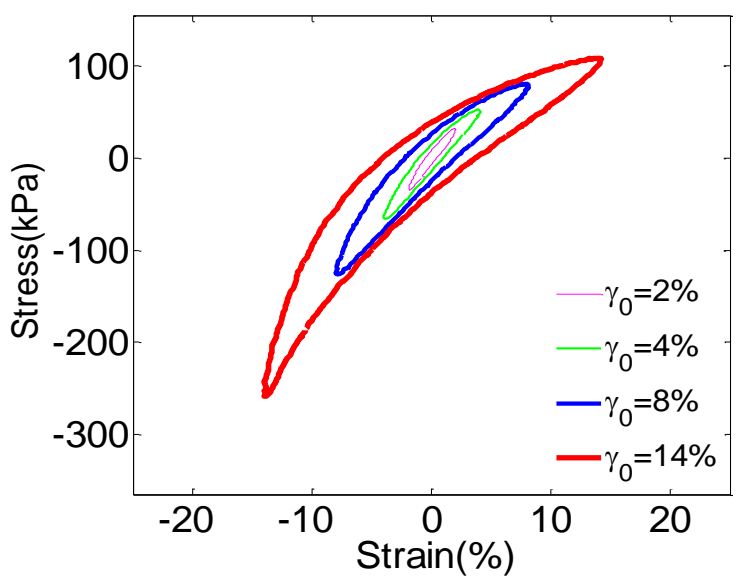

(d)

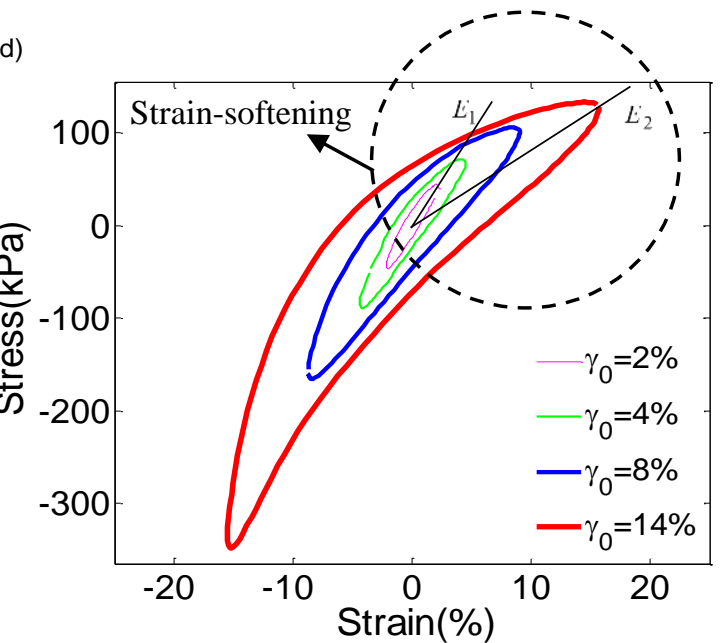

Figure 5. Hysteresis loops with magnetic flux density $B=260 \mathrm{mT}$.

(a) $\mathrm{f}=0.1 \mathrm{~Hz}$, (b) $\mathrm{f}=1 \mathrm{~Hz}$, (c) $\mathrm{f}=3 \mathrm{~Hz}$, (d) $\mathrm{f}=8 \mathrm{~Hz}$

Upon application of a magnetic field, the absolute stress increases for the same strain, but the strain-stiffening in tension disappears while the down-turn in compression remains (Figure 4(a)). Experimentally the maximum absolute value of stress in the cyclic tension-compression test is observed during the compression step, since the extra repulsion between the particles confined in the rubber matrix contribute to the non-linear increase in the elastic stress (Figure 5). When a magnetic field is applied, the added attraction between particles causes even stronger confinement and higher local extension of the polymer between the magnetizable iron particles (Figure 6), the bottoms of the 
graphs are even more asymmetric. A curious feature in Figure 6 is that during tension, the increase of the relative distance between particles allows this attraction between them to rearrange past each other causing the strain softening feature of the curves.

\subsection{The effect of displacement amplitude on hysteresis loops}

The dynamic behavior of MREs depends on the strain, frequency, and magnetic field. Previous models capture some of these dependencies. MREs with viscoelasticity exhibit the Flether-Gent effect [135], also known as the Payne effect [136]. This phenomenon is defined as the decrease of the dynamic modulus with increasing amplitude of oscillation [137]. In other words, the Payne effect is known to be a particular feature of the stress-strain behavior of rubber composites containing fillers, in particular, carbon black [138]. This phenomenon has observed in both shear and compression mode $[117,131]$. The Payne effect is a reversible phenomenon and frequently explained by the breakdown of filler aggregates to release trapped rubber to allow more viscous flow, separation of dipole-dipole interaction between neighboring particle and filler rubber detachment and reformation that increases with increasing strain amplitude [139].

Being composite polymer materials, MREs and MR gels also exhibit the Payne effect. In small amplitude dynamic oscillation, only minor reorganization occurs in the network structure formed by the filler particles. When the strain is increased, the particle network structure begins to break, thus increasing the distance between the dipoles [117]. Therefore, above some critical strain amplitude, the dynamic modulus decreases rapidly with increasing amplitude. Sorokin et al [140] observed that in the absent of magnetic field Payne effect is started at $1 \%$ and $0.1 \%$ amplitude for isotropic MRE and anisotropic MRE, respectively. They showed the storage modulus of isotropic MRE decreases 20$30 \%$ at strains of up to $25 \%$.

Additionally, it is found that the Payne effect significantly increases in the presence of an external magnetic field. Indeed, the magnetic filler network becomes much more active when a magnetic field is applied. Interactions between magnetic particles and their rearrangement cause not only a huge increase in the dynamic moduli but also a strong strain dependence of the moduli. For small deformations, the magnetic filler network is slightly disturbed while large deformations lead to 
destroy the magnetic particles network resulting in material softening. Enhancement of the Payne effect due to the magnetic field has also been reported [132, 141, 142]. Based on the facts mentioned above, the Payne effect reduces the equivalent stiffness of the MRE which is also observable in this study; see Figure 5(d). Figure 4 and Figure 5 illustrate the effects of displacement amplitude on the shape of the hysteresis loop with same strain for magnetic flux density $B=0 \mathrm{mT}$ and $\mathrm{B}=260 \mathrm{mT}$. As expected from the Flether-Gent/Payne effects increasing the displacement amplitude leads to a decrease in the dynamic storage modulus (as indicated by the lower slope of the major axis of stressstrain curves, Figure 5). This strain-softening behavior is more pronounced in the presence of magnetic field; see Figure 5(d). Strain-softening in the absence of magnetic fields appears only weakly at high frequencies; see Figure 4(d), whereas at relatively low frequencies and high displacement amplitude strain-stiffening appears; see Figure 4(a).

(a)

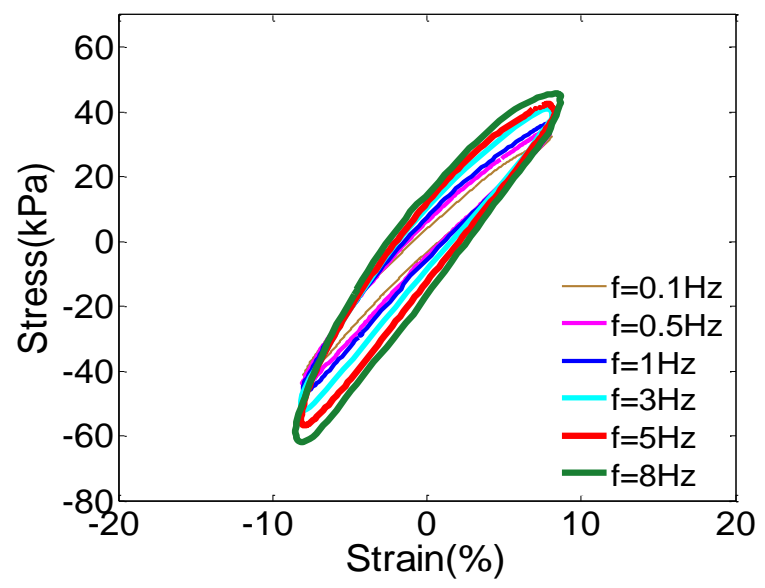

(b)

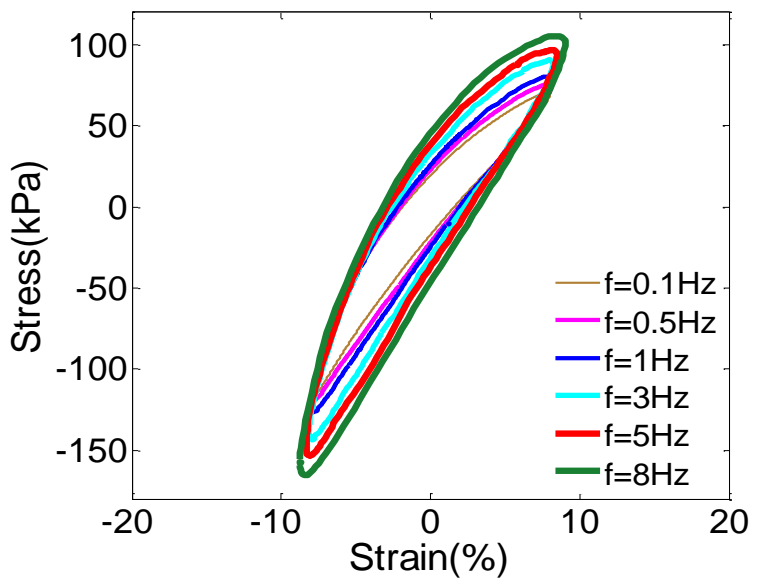

Figure 6. Hysteresis loops under different frequencies with strain $\gamma_{0}=8 \%$ show strain-rate stiffening with increase in driving frequency. Magnetic flux density $B=0 \mathrm{mT}$, (b) Magnetic flux density $B=260 \mathrm{mT}$.

Furthermore, based on the Figure 4 and Figure 5 by increasing the displacement amplitude, the area inside the stress-strain curve is increased, which indicates so is the amount of energy dissipated per a cycle or equivalent damping [132]. Damping in MREs is considered to be ascribed to viscous flow of the rubber matrix, interfacial damping at the interface between the magnetic particles and the 
matrix and magnetism-induced damping through magnetic particle interaction and magnetomechanical damping [143]. Viscous damping of MREs is mainly provided by the rubber matrix which is associated with molecular chain motion in polymers. The interface between magnetic particles and the matrix is also important in determining the damping of MREs. Matrix molecules of MRE can bond to the surface of the particles such that a third phase is formed known as the interphase. The interphase possesses properties distinct from those of the matrix and the particles. The interphase mainly plays the role of transferring stress between the matrix and the reinforced particles. The energy absorption could be attributed to energy required to bring about viscous flow of constrained materials in the vicinity of the particle interfaces, as well as breakdown of interfacial bonding when the applied strain amplitude is high, resulting in transformation of elastic energy into kinetic energy, which then converts into heat. The processes for energy absorption through magnetism-induced damping are increased energy absorbed to overcome inter-particle magnetic interactions as well as magnetomechanical damping (change of magnetic domain structure induced by application of stress); these processes transform elastic energy into magnetic energy which subsequently dissipates by magnetic hysteresis [144-147].

To sum up, there are different mechanisms of MRE during dynamic oscillation, which mechanical energy convert into heat, indicating the overall damping of MRE that is corresponding the area inside the hysteresis loops.

\subsection{The effect of motion frequency on the hysteresis loops}

The effect of the frequency of cycling on the dynamic properties of elastomers has been a concern in engineering applications for a long time. However, assessing the effect of the frequency on the dynamic properties of rubber-like material is difficult to do experimentally due to the obstacles of obtaining a wide range of frequencies using a single apparatus. Generally, increasing the rate of strain increases the dynamic stiffness and loss moduli of the MREs.

The properties of MREs in addition to deformation (strain) are also strain-rate dependent and exhibit a stiffening effect with increase of cycling frequency. Higher frequencies constrain the time for molecular relaxation motions, thus resulting in higher stresses for a given strain and larger 
hysteresis loops. Therefore, the rate of the strain strongly determines the equivalent damping and equivalent stiffness of the MRE measured as area inside the hysteresis loop and slope of the major axis of the hysteresis stress-strain loops. Figure 6 illustrates the effects of frequency on the shape of the hysteresis loops with same strain for magnetic flux densities of $B=0 \mathrm{mT}$ and $\mathrm{B}=272 \mathrm{mT}$. It is plain to see that the slope of the hysteresis loops as well as the captured area in each loop is increased by increasing input frequency both with and without applied magnetic field. However, this increment is more evident for the applied magnetic field case; see Figure 6(b).
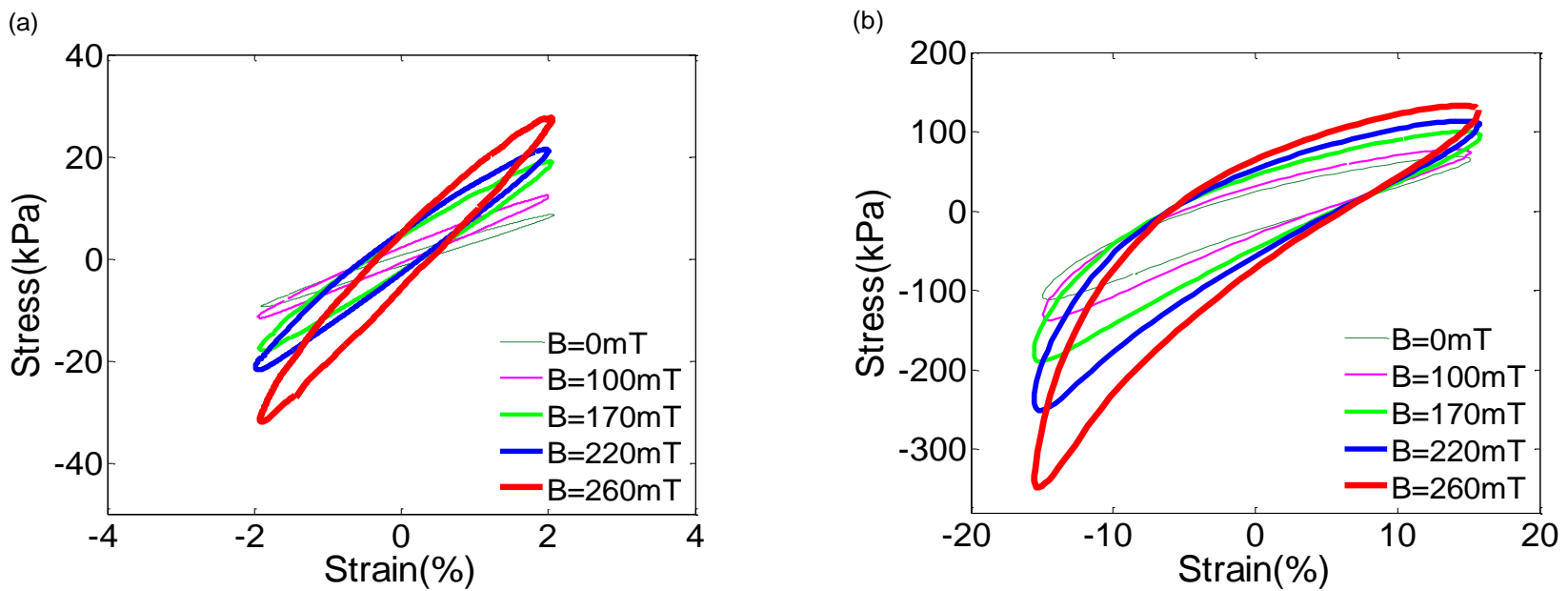

Figure 7. Stress-strain response under different levels of magnetic flux density

(a) $\mathrm{f}=0.1 \mathrm{~Hz}$ and strain $\gamma_{0}=2 \%$, (b) $\mathrm{f}=8 \mathrm{~Hz}$ and strain $\gamma_{0}=14 \%$.

\subsection{The effect of magnetic field on hysteresis loops}

In order to show the effect of magnetic field on the dynamic behavior of MREs, we measured the stress-strain response of MREs to harmonic oscillation at constant frequency and strain for different levels of applied magnetic flux density, from $B=0 \mathrm{mT}$ to $\mathrm{B}=272 \mathrm{mT}$ (shown in Figure 7). By increasing magnetic flux density, for the same strain and the same frequency, the shapes of the hysteresis loops are changed from symmetric ellipsoid to asymmetric for the low-strain cases. The slopes of the hysteresis loops indicating increase in the equivalent stiffness or dynamic storage modulus of the MRE, and so does the area enclosed by the loops, which means the dissipated energy per cycle of MRE is enhanced. 


\section{Modeling}

The experimental results showed a variety of complex dynamic behaviors of MREs in the presence of magnetic fields, different strain amplitudes and loading frequencies. In the dynamic tensioncompression tests the hysteresis loops are often not perfect ellipses, and their magnetic field, strain and strain rate-dependent asymmetries have not been adequately captured by previous models. Our novel phenomenological model for the dynamic characteristics of MRE is able to reproduce the nonlinear viscoelasticity and symmetric and asymmetric hysteresis behavior under all conditions of the tension-compression test.

\subsection{Phenomenological model}

Based on the experimental results, the applied magnetic field through tension-compression cyclic loading result in nonlinear viscoelasticity and asymmetric hysteresis loops. The nonlinear viscoelasticity and hysteresis behavior are expressed by viscoelastic stress and hysteresis stress, respectively. Therefore, In order to predict the response of an MRE in a wide range of dynamic tension-compression regimes, a phenomenological model is adopted, as shown in Figure 8. The proposed model incorporates a nonlinear stiffness and damping element which demonstrate the nonlinear viscoelastic behavior of rubber-like materials under large deformation, in parallel with a hysteresis component, which captures the nonlinear asymmetric hysteresis shape of stress-strain loops. The model also captures how stiffness and damping of the MREs depend on external magnetic flux density, loading frequency and strain. Based on the Figure 4 to Figure 7 dynamic behavior of MRE in tension-compression oscillation depends on loading frequency, strain, and magnetic field. In other words, the dynamic behavior of MRE is recognized by observing the different shapes of experimental hysteresis loops, shown in Figure 9. 


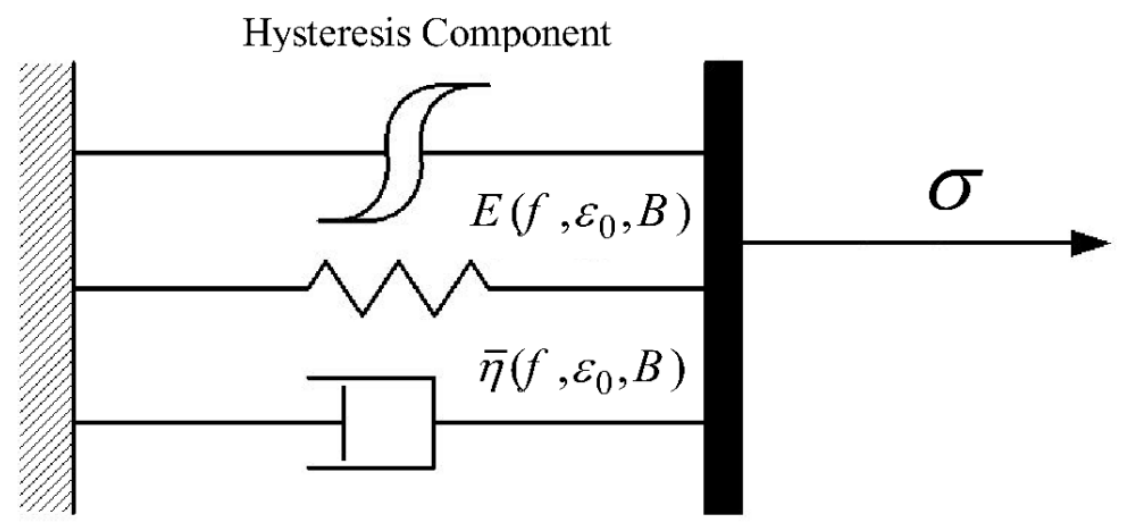

Figure 8. Phenomenological model of MRE.

Table 2. Physical features for the stress-strain hysteresis curves as illustrated in Figure 9.

\begin{tabular}{lll}
\hline Feature & Parameter & Physical meanings \\
\hline F1 & $a_{B}$ & Effect of magnetic field on equivalent stiffness \\
F3 & $b_{B}$ & Strain-rate stiffening behavior \\
F4 & $\alpha_{B}$ & Strain-softening behavior \\
F5 & $\beta$ & Effect of magnetic field on elongational viscosity/ equivalent damping \\
F6 & $\lambda_{1}$ & Effect of strain on equivalent damping \\
F7 & $K_{11 B}$ & Asymmetric hysteresis behavior (tension-compression asymmetry) \\
F8 & $K_{12 B}$ & Effect of loading frequency on asymmetric hysteresis behavior \\
F9 & $K_{13 B}$ & Effect of strain on asymmetric hysteresis behavior \\
F10 & $K_{21 B}$ & Strain stiffening behavior
\end{tabular}



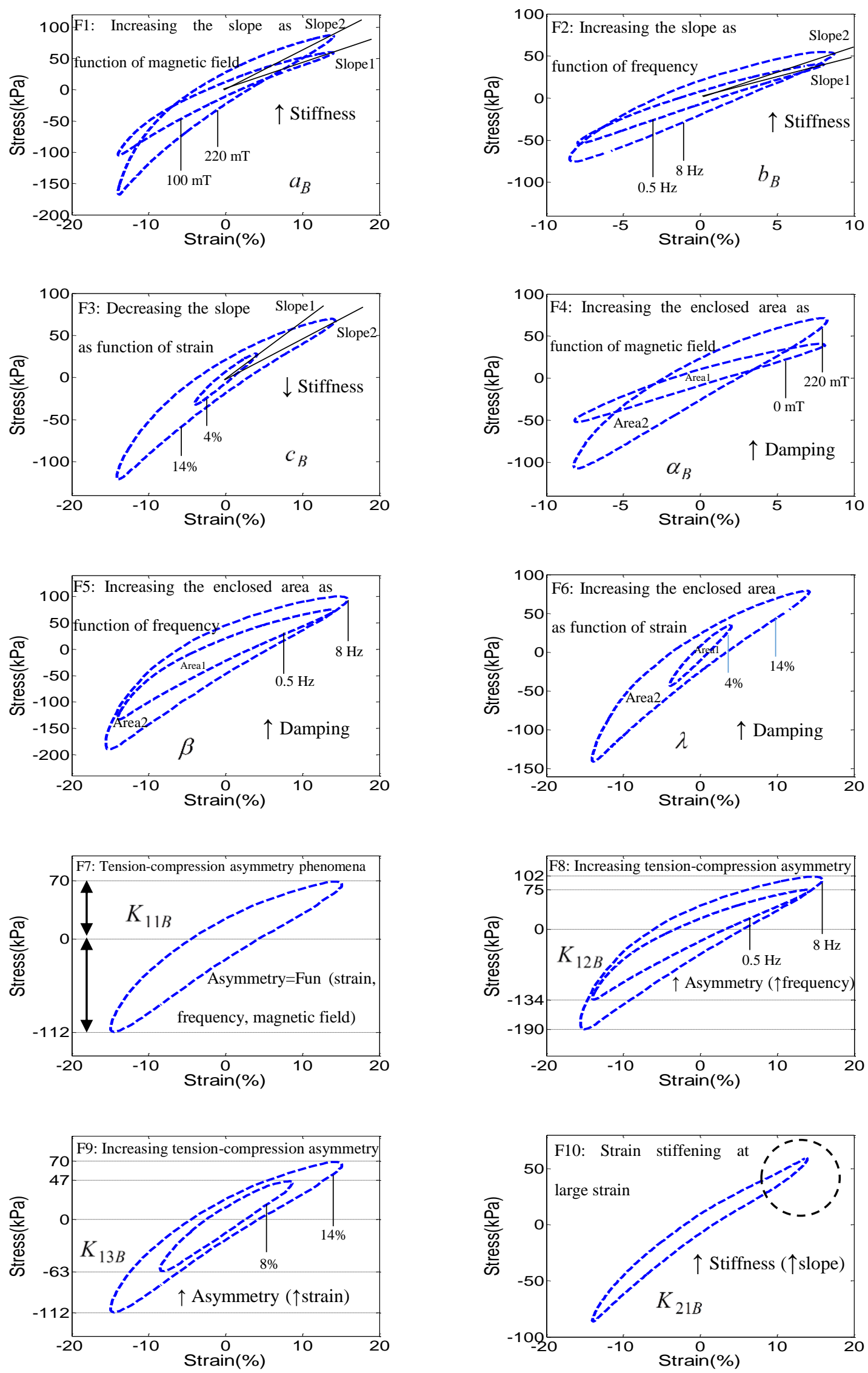

Figure 9. Features for the stress-strain hysteresis curves and parameters that change them. 
Therefore, the proposed model should predict all these different hysteresis loops, representing particular physical features, by incorporating specific parameters mentioned in the Table 2. Based on the Table 2, for example, by increasing the magnetic field both equivalent stiffness and damping of MRE are increased. The physical meanings of these features as well as their schematic interpretations are mentioned in the Table 2 and Figure 9, respectively.

Based on the points mentioned above, Table 2 lists the different dynamic features of MRE should use in this model and Figure 9 illustrates the effects of those features on the shapes of stress-strain hysteresis curves of MRE obtained in tension-compression experiments. Additionally, based on these curves, the physical meanings of the parameters are revealed as different properties of the MRE.

\subsection{Viscoelastic and hysteresis component}

The stress-strain relationship of the MRE model in dynamic tension-compression shown in Figure 8 is given as below.

$$
\begin{aligned}
& \sigma_{\text {MRE }}=\sigma_{\text {Viscoelastic }}+\sigma_{\text {Hysteresis }} \\
& \sigma_{\text {Viscoelastic }}=E\left(f, \varepsilon_{0}, \mathrm{~B}\right) \varepsilon(t)+\bar{\eta}\left(f, \varepsilon_{0}, \mathrm{~B}\right) \dot{\varepsilon}(t) \\
& \sigma_{\text {Hysteresis }}=K_{1}\left(f, \varepsilon_{0}, \mathrm{~B}\right) \varepsilon^{2}(t)+K_{2}(\mathrm{~B}) \varepsilon^{3}(t)
\end{aligned}
$$

where $\sigma(\mathrm{t})$ and $\varepsilon(\mathrm{t})$ are stress output and strain input, $E\left(f, \varepsilon_{0}, \mathrm{~B}\right)$ and $\bar{\eta}\left(f, \varepsilon_{0}, \mathrm{~B}\right)$ are the dynamic storage modulus (equivalent stiffness) and loss modulus (effective viscosity, equivalent damping) which measure the potential for storing and dissipating energy, respectively. Furthermore, $f, f_{0}, \varepsilon_{0}$, and $B$ are the loading frequency, reference frequency $(1 \mathrm{~Hz})$, displacement amplitude, and magnetic flux density, respectively.

We take the strain input $\varepsilon(\mathrm{t})$ to be a harmonic excitation, easily achievable in testing:

$$
\varepsilon(t)=\varepsilon_{0} \sin (2 \pi f t)
$$


Suppose also that in this model the dynamic storage modulus $E\left(f, \varepsilon_{0}, \mathrm{~B}\right)$ and elongational viscosity $\bar{\eta}\left(f, \varepsilon_{0}, \mathrm{~B}\right)$ are represented as following:

$$
\begin{aligned}
& E\left(f, \varepsilon_{0}, B\right)=a_{B}\left(\frac{f}{f_{0}}\right)^{b_{B}}\left(\varepsilon_{0}\right)^{c_{B}} \\
& \bar{\eta}\left(f, \varepsilon_{0}, B\right)=\alpha_{B}\left(\frac{f}{f_{0}}\right)^{\beta}\left(\varepsilon_{0}\right)^{\lambda}
\end{aligned}
$$

and the $K_{1}\left(f, \varepsilon_{0}, \mathrm{~B}\right)$ and $K_{2}(\mathrm{~B})$ represent the asymmetric hysteresis (or tension-compression asymmetry) and strain-stiffening behavior, respectively. These components, constructing the hysteresis element, are indicated as below:

$$
\begin{aligned}
& K_{1}\left(f, \varepsilon_{0}, \mathrm{~B}\right)=k_{11 B}\left(\frac{f}{f_{0}}\right)^{k_{12 B}}\left(\varepsilon_{0}\right)^{k_{13 B}} \\
& K_{2}(\mathrm{~B})=k_{21 B}
\end{aligned}
$$

The physical interpretation of the model's parameters are described in the Table 2.

According to Figure 8, the new phenomenological model consists of four main components including $E\left(f, \varepsilon_{0}, B\right), \bar{\eta}\left(f, \varepsilon_{0}, B\right), \quad K_{1}\left(f, \varepsilon_{0}, \mathrm{~B}\right) \quad$ and $\quad K_{2}(\mathrm{~B}) \quad$ are determined based on the corresponding magnetic flux density, frequency and strain by equation (5) through equation (8) . Regarding the equation (5) through equation (8), the four main components of proposed models constructed based on the ten parameters which are mentioned in the Table 2.

The proposed model uses strain as an input and then calculates the dynamic storage modulus $E\left(f, \varepsilon_{0}, B\right)$, elongational viscosity $\bar{\eta}\left(f, \varepsilon_{0}, B\right)$ and the hysteresis component of the MRE. Afterwards, it gives the stress determined by equation (1).

MRE stiffness and damping are represented by power functions of frequency and displacement amplitude, see equations (5) and (6). These power functions are chosen based on the variation of the slope of hysteresis loops by increasing frequency from $0.5 \mathrm{~Hz}$ to $8 \mathrm{~Hz}$. If we go beyond this range of 
frequency, we predict the trend of variation of will not dramatically change due to the general trend of MRE with respect of strain, frequency and magnetic field are available and observable. The power and coefficients of these power functions can easily be modified slightly for extrapolating new range of loading conditions such as frequency, strain and magnetic field. For example, if some experimental data of MRE in tension-compression oscillation beyond the range of this study for instance the frequency of $(1 \mathrm{~Hz}$ to $20 \mathrm{~Hz})$ are available, we could capture the new trend by slightly changing the power and coefficients of the related power function of frequency without implementing new optimization. Since the proposed MRE is mostly aimed at seismic protection of buildings and infrastructures, which the most devastating frequency range is below $5 \mathrm{~Hz}$, the experimental investigation implemented in this research is adequate to provide the target. Furthermore, this range of frequency $(0.5 \mathrm{~Hz}$ to $8 \mathrm{~Hz})$ cover both typical low frequency and high frequency, at least, for application of vibration isolation of infrastructures. Moreover, the operating frequency of automobiles usually varies from 0.1 to $10 \mathrm{~Hz}[148]$.

\subsection{Parameter Identification}

The model's parameters, mentioning in Table 2 are calculated by fitting the model-predicted stress $\tau_{\text {Model }}$ to the experimental stress $\tau_{E x p}$. The fitting process is done by minimizing the error $\left(\tau_{\text {Model }}-\tau_{\text {Exp }}\right)$ through implementing the least squares method; see equation (9). This minimization is implemented at each external magnetic flux density, including $0 \mathrm{mT}, 100 \mathrm{mT}, 170 \mathrm{mT}, 220 \mathrm{mT}$ and $260 \mathrm{mT}$, for all loading frequencies and input strains in order to remove the dependency of model's parameters to the loading frequency and strain. Hence, this optimization is implemented just for five times (different magnetic flux densities). Consequently, the parameters will depend only on the magnetic flux density; finally, the constant coefficients of these magnetic field dependent parameters will be calculated by using nonlinear curve fit method; see Table 5 . The difference between the model and experiment is represented by a fitness function error as below:

$$
f f=\sum_{i=1}^{N} \sum_{j=1}^{M}\left(\tau_{\text {Model }}(i, j)-\tau_{E x p}(i, j)\right)^{2}
$$


1

2

where $N$ and $M$ are the number of different experimental data sets of motion frequency and displacement amplitude, respectively. This optimization is done at different magnetic fields. These parameters are calculated and expressed in Table 3 and Table 4.

From these tables, it is found that the parameters $a, b, c, \alpha, k_{11}, k_{12}, k_{13}$, and $k_{21}$ are magnetic field dependent whereas the parameters $\beta$ and $\lambda$ are constant by varying magnetic field. By increasing the magnetic flux density, the absolute value of the parameters $a, b, c, k_{11}, k_{12}$ and $k_{21}$ are changed quadratically while $k_{13}$ and $\alpha$, are increased steadily and exponentially, respectively. At this case, a nonlinear curve fit was implemented to these parameters. The constant coefficients of magnetic-field dependent parameters are calculated and listed in Table 5.

Table 3. Magnetic field dependent parameters of phenomenological model.

\begin{tabular}{cclllllll}
\hline $\begin{array}{l}\text { Magnetic flux } \\
\text { density }(\mathrm{mT})\end{array}$ & $a_{B}(\mathrm{kPa})$ & $b_{B}$ & $c_{B}$ & $\alpha_{B}(\mathrm{kPa})$ & $k_{11 B}(\mathrm{kPa})$ & $k_{12 B}$ & $k_{13 B}$ & $k_{21 B}(\mathrm{kPa})$ \\
\hline 0 & & & & & & & & \\
\hline 100 & 6.034 & 0.0862 & -0.1107 & 0.1235 & -0.2646 & 0.2374 & -0.5843 & 0.0039 \\
170 & 8.092 & 0.0886 & -0.1652 & 0.2485 & -0.2736 & 0.2431 & -0.4408 & 0.0045 \\
220 & 13.11 & 0.0868 & -0.2699 & 0.4161 & -0.3648 & 0.1984 & -0.3835 & 0.0071 \\
260 & 15.38 & 0.0944 & -0.2917 & 0.5146 & -0.3897 & 0.1719 & -0.2569 & 0.0140 \\
\hline
\end{tabular}

Table 4. Constant parameters of phenomenological model.

\begin{tabular}{ccc}
\hline Magnetic flux density $(\mathrm{mT})$ & $\beta$ & $\lambda$ \\
\hline 0 & 0.7930 & 0.1086 \\
100 & 0.7930 & 0.1086 \\
170 & 0.7930 & 0.1086 \\
220 & 0.7930 & 0.1086 \\
260 & 0.7930 & 0.1086 \\
\hline
\end{tabular}

thus, the six polynomial functions, a linear function and an exponential function are determined from nonlinear curve fit that are expressed as below:

$$
a_{B}=a^{\prime} B^{2}+a^{\prime \prime} B+a^{\prime \prime \prime}
$$




$$
\begin{aligned}
& b_{B}=b^{\prime} B^{2}+b^{\prime \prime} B+b^{\prime \prime \prime} \\
& c_{B}=c^{\prime} B^{2}+c^{\prime \prime} B+c^{\prime \prime \prime} \\
& \alpha_{B}=\alpha^{\prime} \exp \left(\alpha^{\prime \prime} \mathrm{B}\right) \\
& k_{11 B}=k_{11}{ }^{\prime} B^{2}+k_{11}^{\prime \prime} B+k_{11}^{\prime \prime \prime} \\
& k_{12 B}=k_{12}{ }^{\prime} B^{2}+k_{12}{ }^{\prime \prime} B+k_{12}^{\prime \prime \prime} \\
& k_{13 B}=k_{13}{ }^{\prime} B+k_{13}^{\prime \prime} \\
& k_{21 B}=k_{21}^{\prime} B^{2}+k_{21}^{\prime \prime} B+k_{21}^{\prime \prime \prime}
\end{aligned}
$$

The modeling results are given in Figure 14 through Figure 19, which coincide well with the experimental results.

Table 5. Constant coefficients of magnetic field dependent parameters of proposed model.

\begin{tabular}{ll}
\hline Parameter & Value \\
\hline$a^{\prime}\left(\mathrm{kPa} /(\mathrm{mT})^{2}\right)$ & $2 \times 10^{-4}$ \\
$a^{\prime \prime}(\mathrm{kPa} / \mathrm{mT})$ & $-6.2 \times 10^{-3}$ \\
$a^{\prime \prime \prime}(\mathrm{kPa})$ & 6.1217 \\
$b^{\prime}\left(1 /(\mathrm{mT})^{2}\right)$ & $-1.383 \times 10^{-7}$ \\
$b^{\prime \prime}(1 / \mathrm{mT})$ & $-4.502 \times 10^{-5}$ \\
$b^{\prime \prime \prime}$ & $8.586 \times 10^{-2}$ \\
$c^{\prime}\left(1 /(\mathrm{mT})^{2}\right)$ & $6.282 \times 10^{-7}$ \\
$c^{\prime \prime}(1 / \mathrm{mT})$ & $-9.508 \times 10^{-4}$ \\
$c^{\prime \prime \prime}$ & $-1.035 \times 10^{-1}$ \\
$\alpha^{\prime}(\mathrm{kPa} . \mathrm{s})$ & $1.188 \times 10^{-1}$ \\
$\alpha^{\prime \prime}(1 / \mathrm{mT})$ & $4.8 \times 10^{-3}$
\end{tabular}




$$
\begin{array}{ll}
k_{11}^{\prime}\left(\mathrm{kPa} /(\mathrm{mT})^{2}\right) & -4 \times 10^{-6} \\
k_{11}^{\prime \prime}(\mathrm{kPa} / \mathrm{mT}) & 2 \times 10^{-4} \\
k_{11}^{\prime \prime \prime}(\mathrm{kPa}) & -2.626 \times 10^{-1} \\
k_{12}^{\prime}\left(1 /(\mathrm{mT})^{2}\right) & -4 \times 10^{-6} \\
k_{12}^{\prime \prime}(1 / \mathrm{mT}) & 4 \times 10^{-4} \\
k_{12}^{\prime \prime \prime} & 2.365 \times 10^{-1} \\
k_{13}^{\prime}(1 / \mathrm{mT}) & 1.6 \times 10^{-3} \\
k_{13}^{\prime \prime} & -6.022 \times 10^{-1} \\
k_{21}^{\prime}\left(\mathrm{kPa} /(\mathrm{mT})^{2}\right) & 4 \times 10^{-7} \\
k_{21}^{\prime \prime}(\mathrm{kPa} / \mathrm{mT}) & -4 \times 10^{-5} \\
k_{21}^{\prime \prime \prime}(\mathrm{kPa}) & 4 \times 10^{-3}
\end{array}
$$

\subsection{Schematic interpretation of the main components of proposed model}

To demonstrate the dynamic features of presented model and the effect of model's components on the hysteresis shapes, a graphical approach is implemented and depicted the performance of the model through Figure 10 through Figure 13. Figure 10 shows the relationships between stress and strain for variations in equivalent stiffness $(E)$. By incrementing the equivalent stiffness $(E)$ the slope of hysteresis loop is increased. Figure 11 illustrates the shape change of stress-strain curves with $\bar{\eta}$. The enclosed area of hysteresis loop is greater with increasing the equivalent damping $(\bar{\eta})$. Figure 12 and Figure 13 depict the shape change of asymmetric hysteresis loops. The parameter $K_{1}$ describes the effect of coupled tension-compression test and strain softening behavior of MRE under cyclic loading. The parameter $K_{2}$ shows the strain stiffening effect of MRE in the absence of magnetic flux density, particularly, warping for large value of $K_{2}$. 


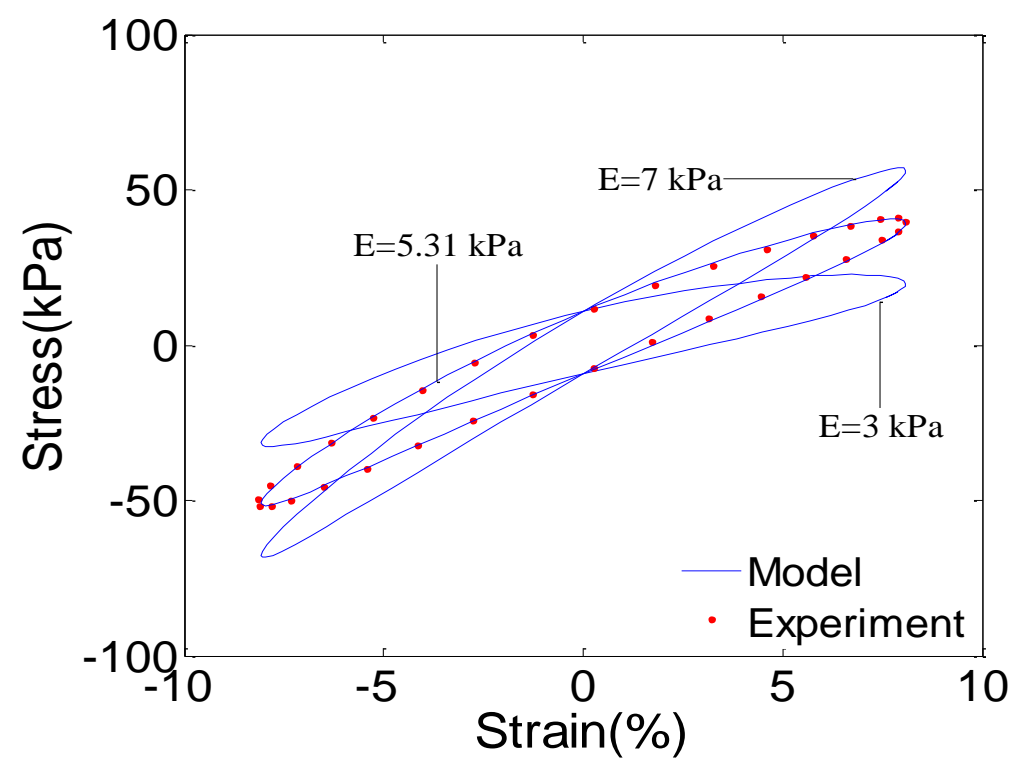

Figure 10. Stress-strain curves for different equivalent stiffness $E$.

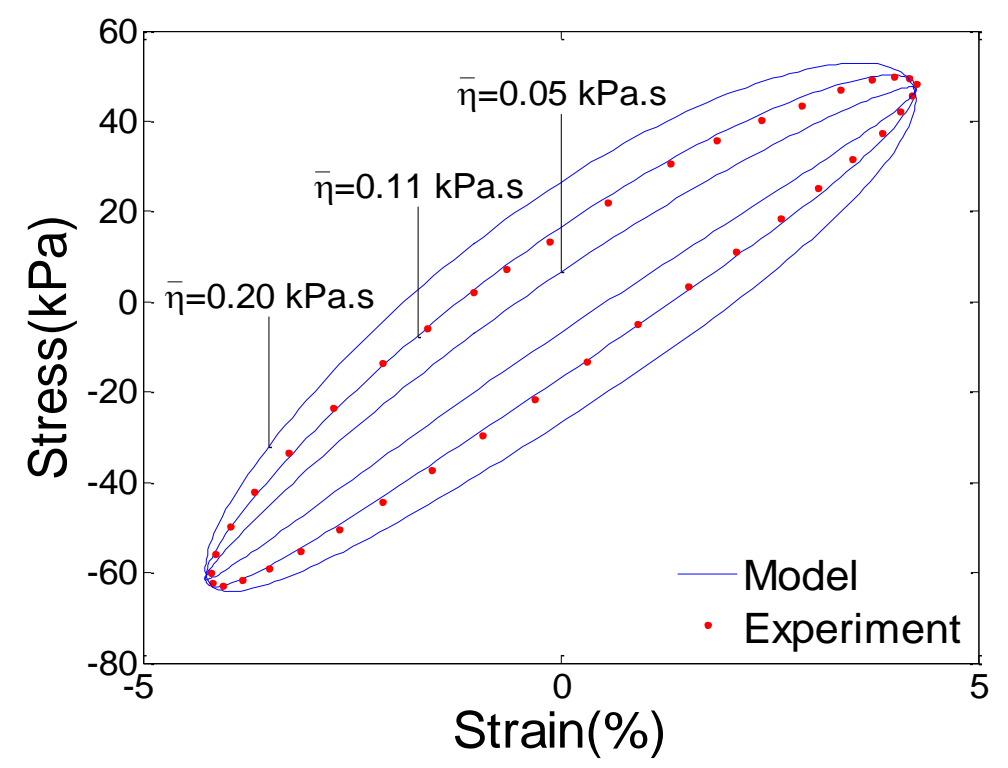

Figure 11. Stress-strain curves for different equivalent damping $\bar{\eta}$. 


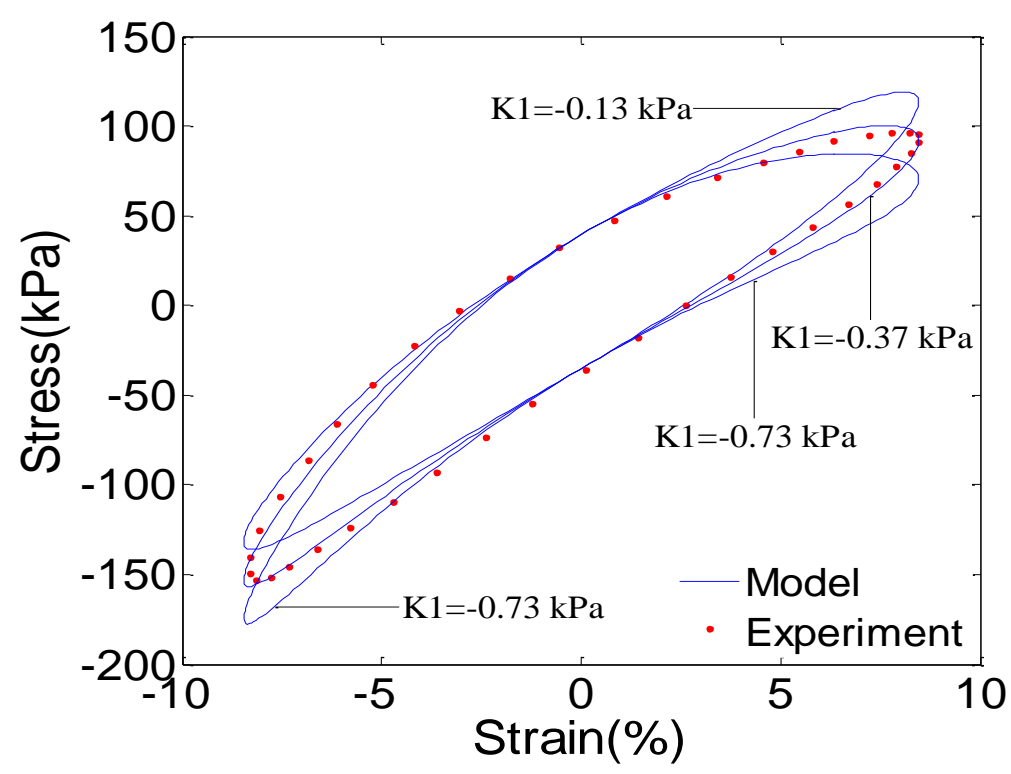

Figure 12. Stress-strain curves for different hysteresis parameters $K_{1}$.

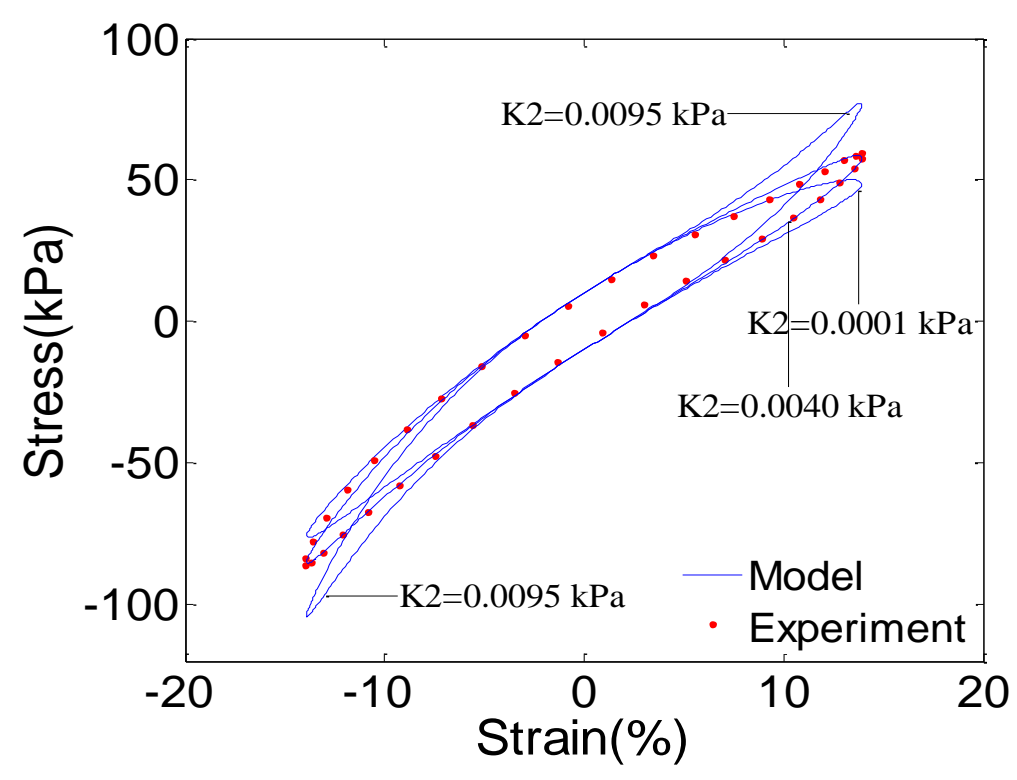

Figure 13. Stress-strain curves for different hysteresis parameters $K_{2}$.

\section{Comparsion of experimetal data and model's response}

\subsection{Model's estimation at training experimental data}

In order to portray the performance of the presented model, the responses of MRE under tensioncompression oscillation are plotted versus experimental loops. There are four levels for strain $(2 \%, 4$ $\%, 8 \%$, and $14 \%$ ), five levels for motion frequency $(0.5 \mathrm{~Hz}, 1 \mathrm{~Hz}, 3 \mathrm{~Hz}, 5 \mathrm{~Hz}$, and $8 \mathrm{~Hz})$ and five 
levels for magnetic flux density $(0 \mathrm{mT}, 100 \mathrm{mT}, 170 \mathrm{mT}, 220 \mathrm{mT}$, and $260 \mathrm{mT})$ utilizing in modeling procedure. Totally, 100 sets of experimental data are prepared as stress-strain hysteresis loops that can be predicted only by proposed model in a wide range of variations in values of magnetic flux density, loading frequency and displacement amplitude. Eight magnetic field dependent parameters are listed in Table 3 and two constants, $\lambda$ and $\beta$, are presented in Table 4. By using these parameters from system identification methodology, the comparison of experimental results and model prediction is shown in Figure 14 through Figure 19.

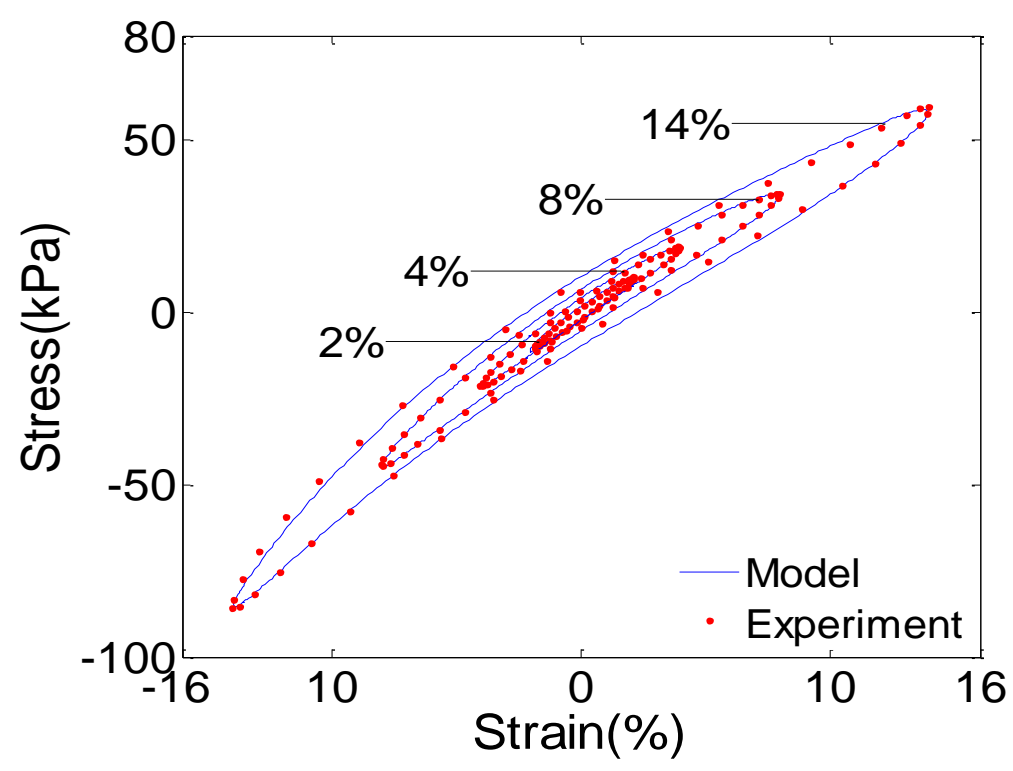

Figure 14. The stress-strain curves of experimental data and proposed model for different strains at loading frequency of $0.5 \mathrm{~Hz}$ and magnetic flux density of $\mathrm{B}=0 \mathrm{mT}$. 


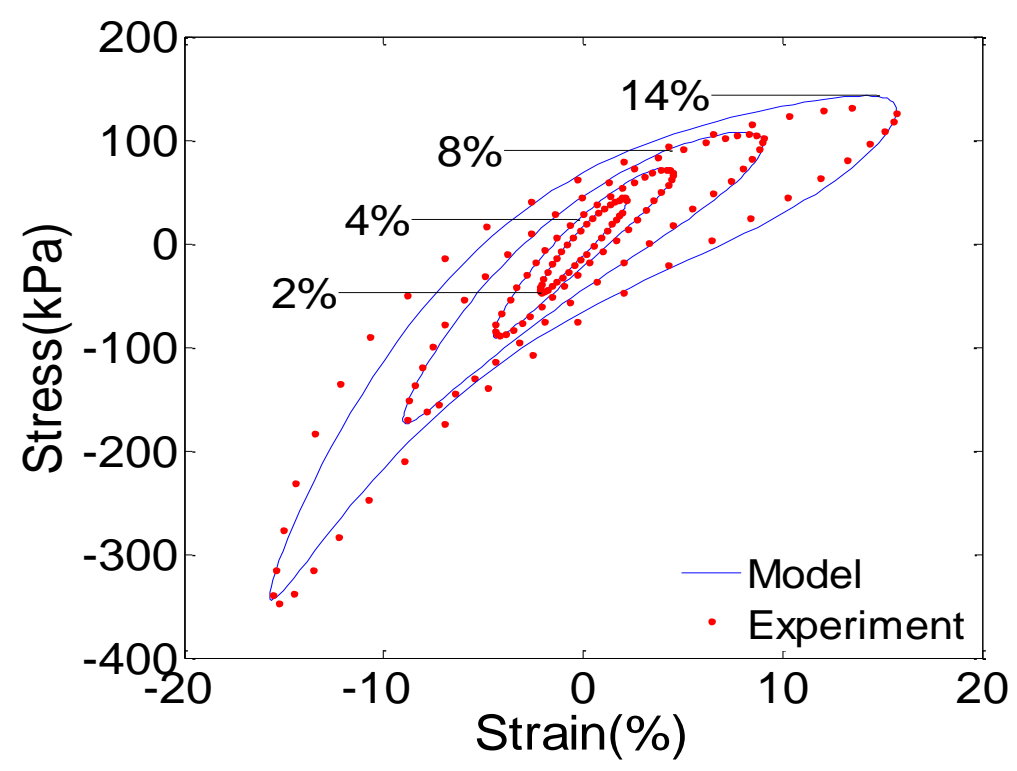

Figure 15. The stress-strain curves of experimental data and proposed model for different strains at loading frequency of $8 \mathrm{~Hz}$ and magnetic flux density of $\mathrm{B}=260 \mathrm{mT}$.
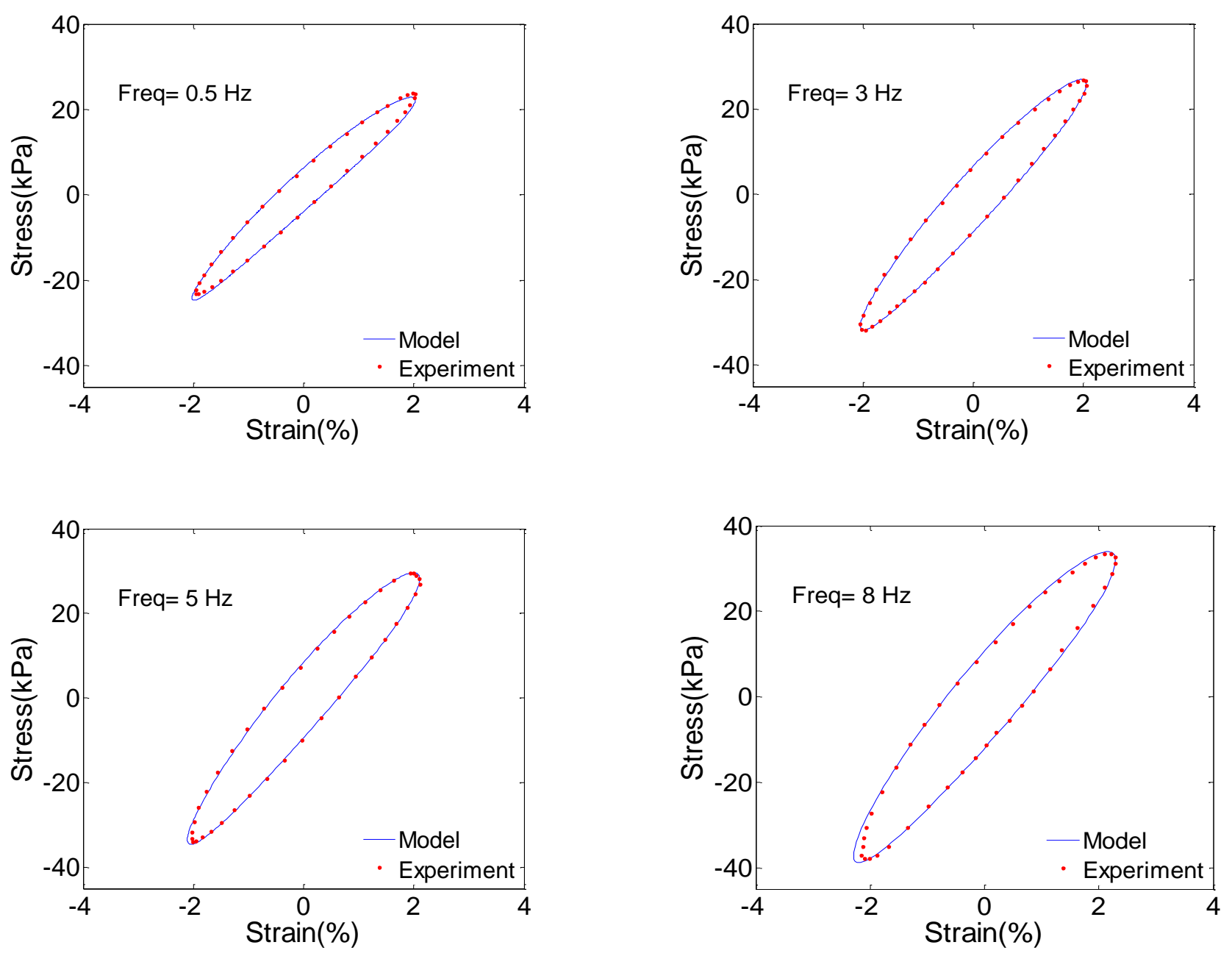
Figure 16. The stress-strain curves of experimental data and proposed model for different input frequencies at strain of $2 \%$ and magnetic flux density of $220 \mathrm{mT}$.
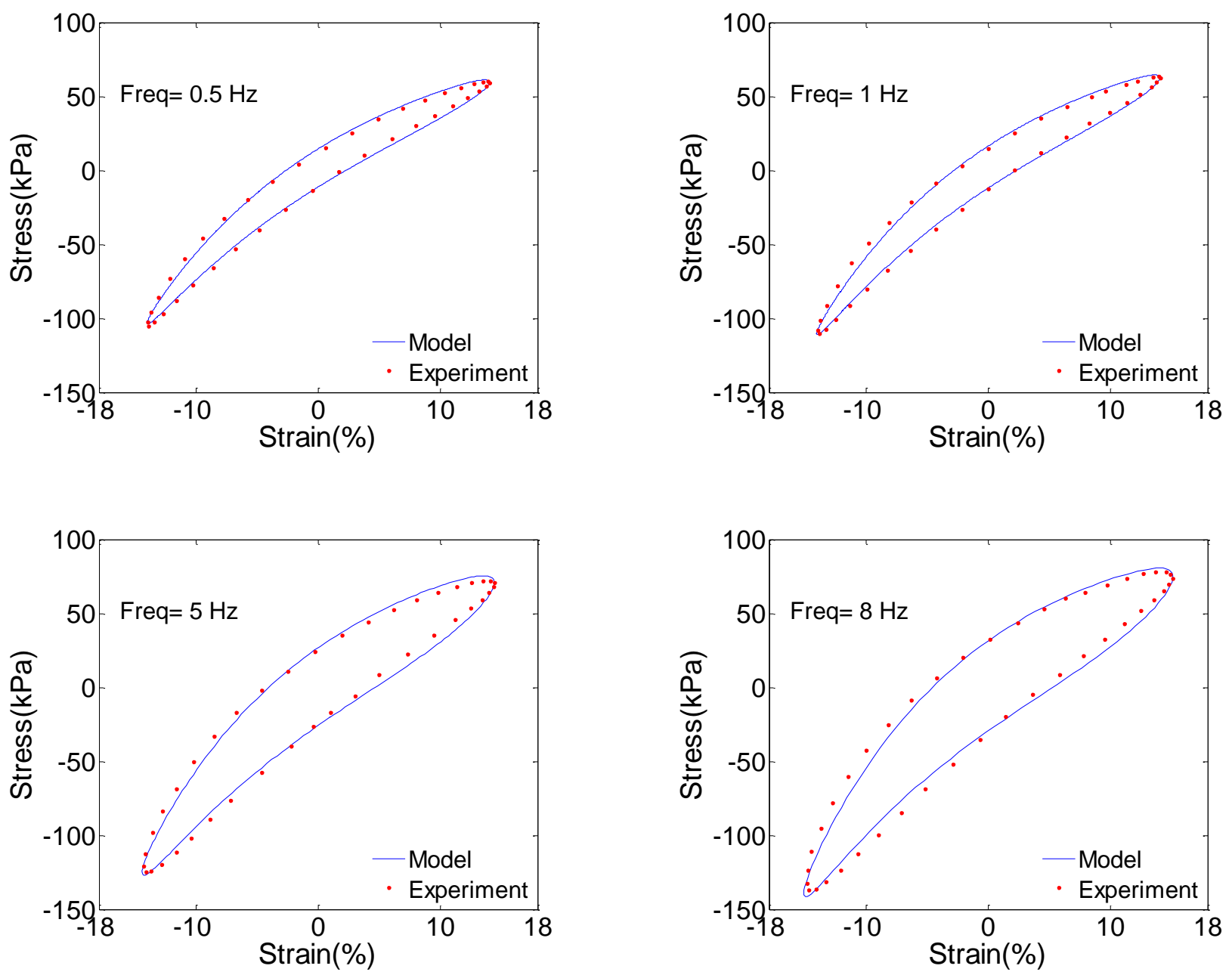

Figure 17. The stress-strain curves of experimental data and proposed model for different input frequencies at strain of $14 \%$ and magnetic flux density of $100 \mathrm{mT}$. 

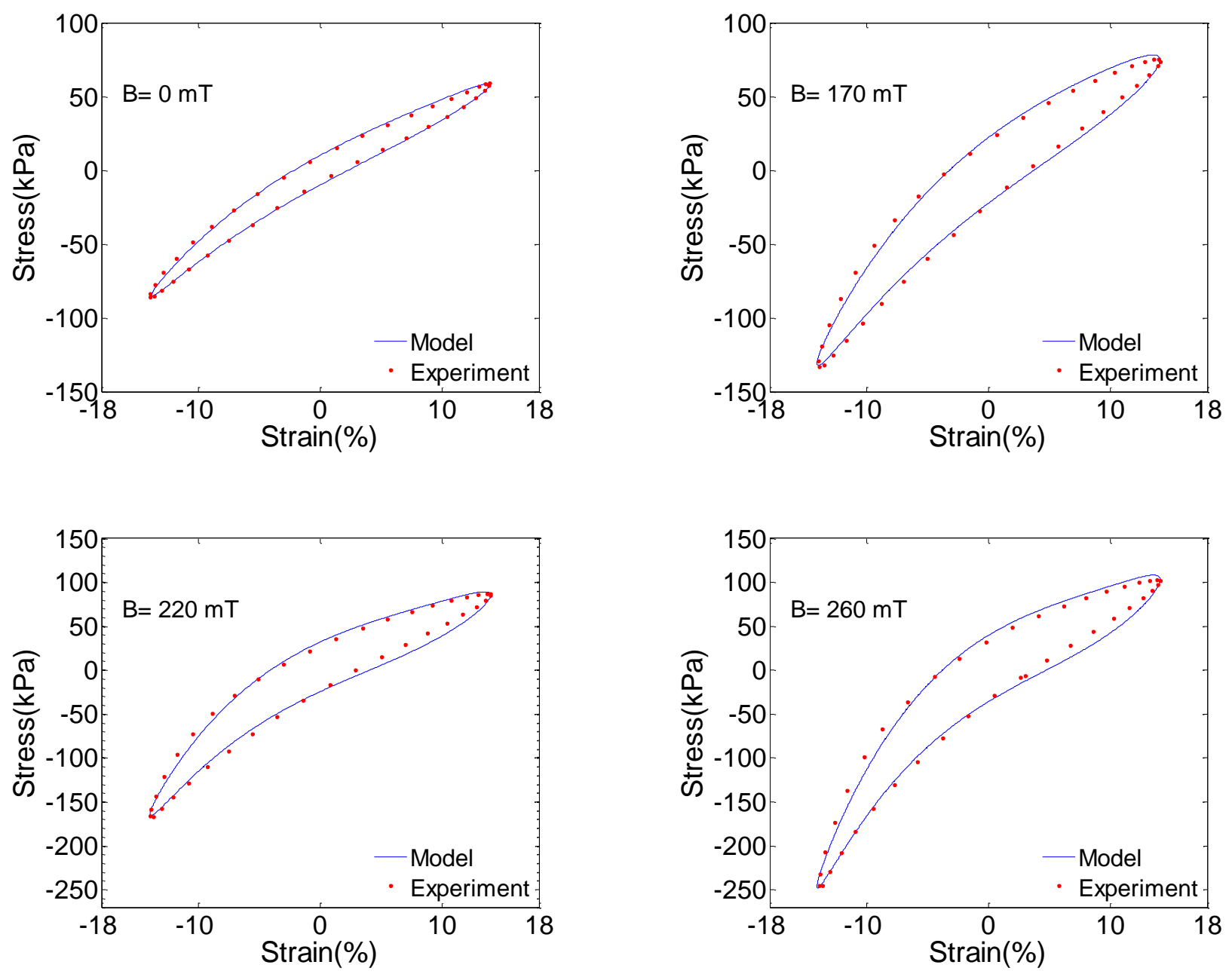

Figure 18. The stress-strain curves of experimental data and proposed model for different magnetic flux densities at strain of $14 \%$ and loading frequency of $0.5 \mathrm{~Hz}$. 

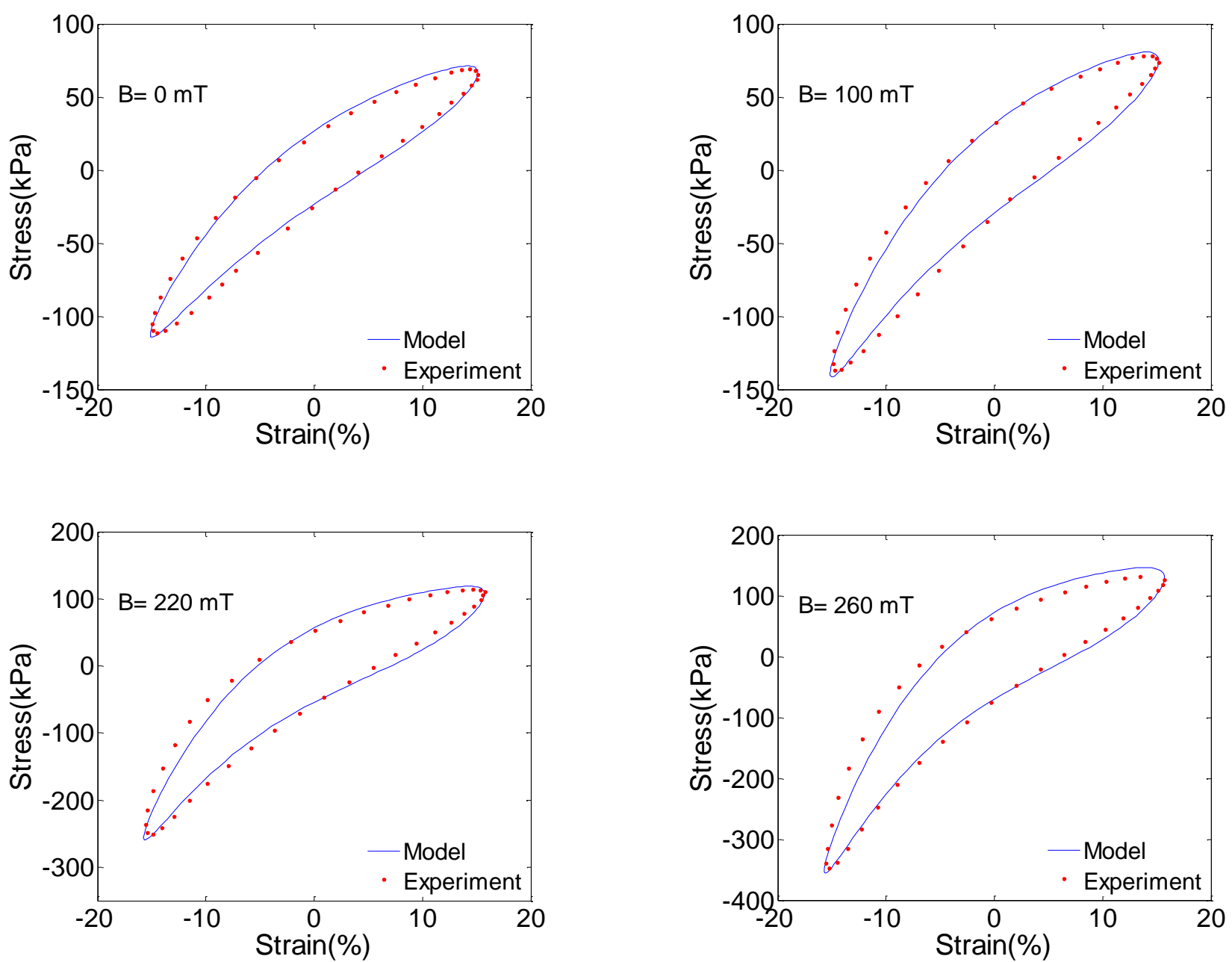

Figure 19. The stress-strain curves of experimental data and proposed model for different magnetic flux densities at strain of $14 \%$ and loading frequency of $8 \mathrm{~Hz}$.

Figure 14 shows the stress-strain relationship of MRE at different strains in the absence of magnetic flux denstiy which strain stiffnening effect is appear at large strain. It can be seen from the figures that the model's estimation is fitted perfectly to experimntal results. Also, the strain softening 
and strain stiffening effect are accurately captured by proposed model. Based on the Figure 15 the strain-softening effect becomes more evident at the high frequency and also for high magnetic flux densities. Additionally, the area of hysteresis loops is increased by increasing the strain, which is predicted by proposed model very well. As shown in Figure 16 and Figure 17, the model pridection is completely in accordance with experimental results and strain-rate stiffening is captured by the proposed model, properly. These figures show that by increasing the motion frequency the enclosed area and the slope of main axis of hysteresis loops are increased. Furthermore, based on the Figure 17 the effect of applying of magnetic flux density on nonlinear asymmetric hysteresis shape of MREs is obvious.

Figure 18 and Figure 19 show the effect of magnetic flux density on mechanical properties of MREs that is appropriately predicted by this phenomenological model. It can be seen from these figures that by increasing the external magnetic flux density, the slopes of the main axes and areas of hysteresis loops are increasing and are captured by the proposed model.

\subsection{Model's performance at outside of training experimental data}

The second method to investigate the model's prediction, is checking the model's response out of the MRE sample training tests which model's parameters are constructed based on them. This is a more challenging way to gauge the efficiency of a phenomenological mode, as the model's predictions are compared to outside of the calibration or training experimental data.
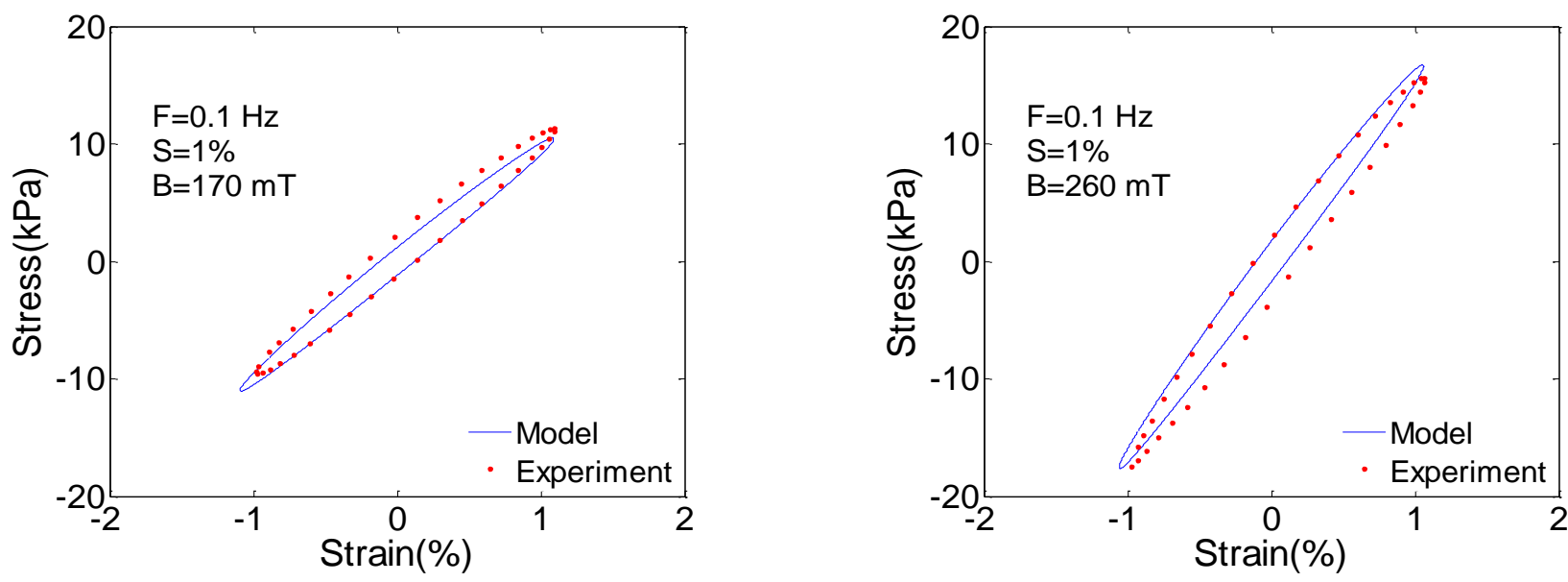

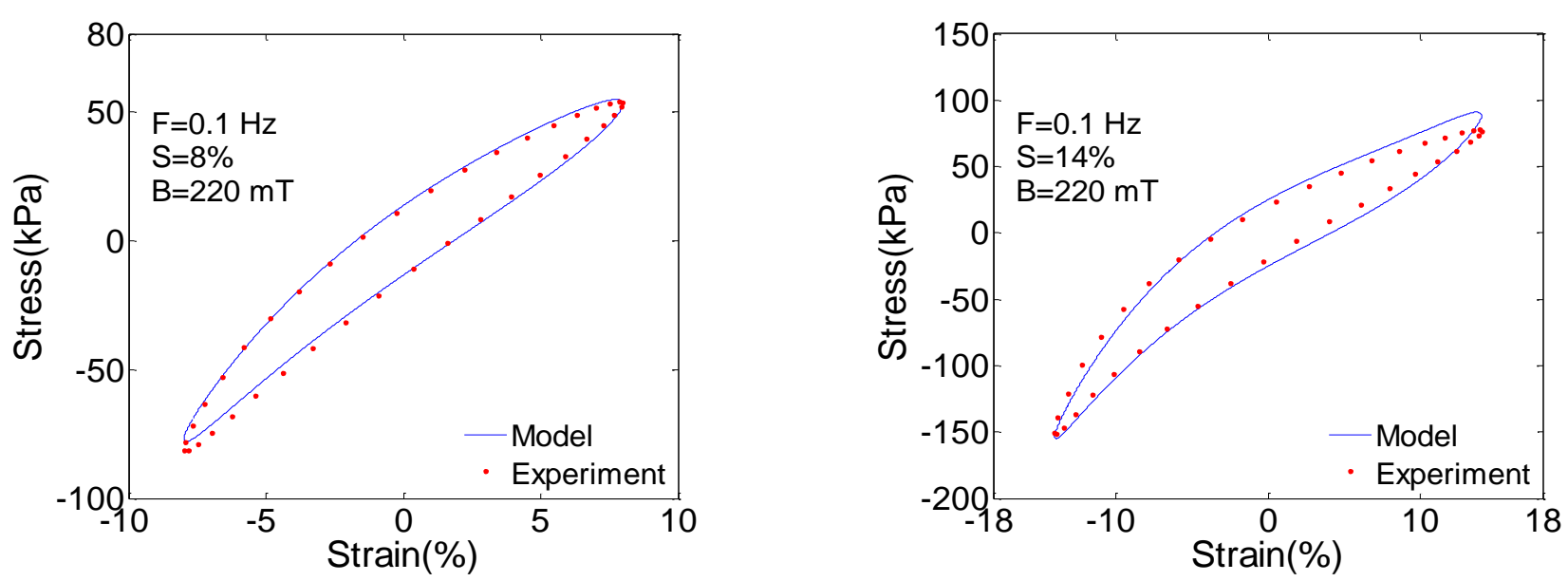

Figure 20. The stress-strain curves of secondary experimental data and proposed model for different magnetic flux densities and strains at loading frequency of $0.1 \mathrm{~Hz}$.
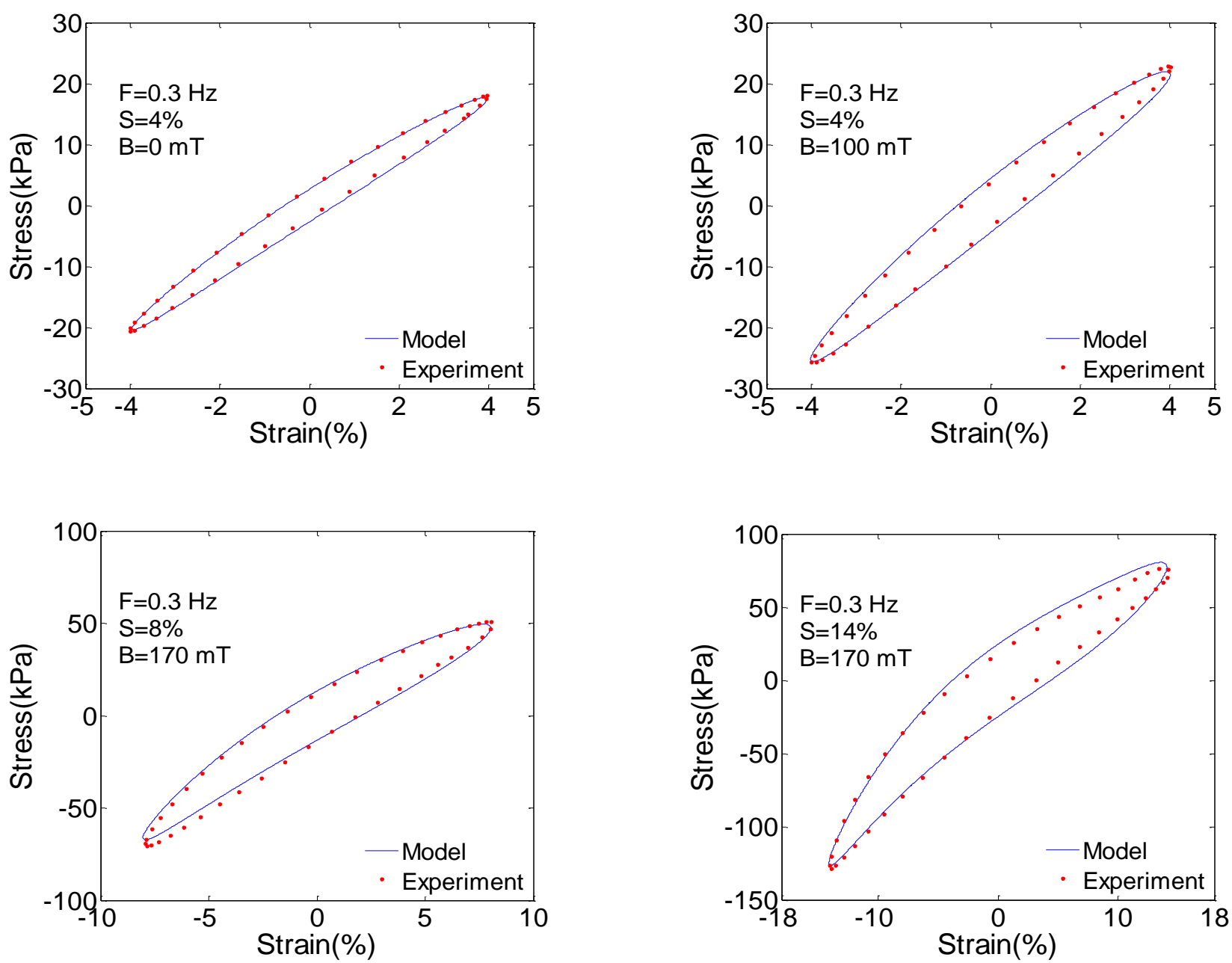

Figure 21. The stress-strain curves of secondary experimental data and proposed model for different magnetic flux densities and strains at loading frequency of $0.3 \mathrm{~Hz}$. 
According to Figure 20 and Figure 21 the proposed model can predict dynamic behavior of MRE at out of calibration experimental range, approximately well.

\section{Quantitative assessment of the proposed model}

The comparison of experimental data and proposed model is shown in Figure 14 through Figure 19. In addition to the graphical presentations, the predictive performance of the present model is investigated through a quantitative survey for all experiment cases such as different magnetic flux densities, frequencies and displacement amplitudes. The Root Mean Square Error (RMSE) (also called the root mean square deviation, RMSD) is a frequently used for measuring of the difference between values predicted by a model and the values actually observed from the experiment that is being modelled. The RMSE of a model prediction is defined as the square root of the mean squared error:

$$
R M S E=\sqrt{\frac{\sum_{i=1}^{n}\left(\tau_{\text {model }, \mathrm{i}}-\tau_{\text {exp }, \mathrm{i}}\right)^{2}}{n}}
$$

where $\tau_{\text {Model }}$ and $\tau_{\text {Exp }}$ are the predicted stress obtained by proposed model and experimental stress obtained by the experiments, respectively. The calculated RMSE values, however, will have units such as $\mathrm{kPa}$; then, the non-dimensional forms of the RMSE are used because often one wants to compare RMSE with different units. So, the following function is used to compute fitness value (1error) [126]:

$$
\text { fitnessvalue }(\%)=100 \times\left[1-\frac{\operatorname{norm}\left(\tau_{\text {Model }}-\tau_{\text {Exp }}\right)}{\operatorname{norm}\left(\tau_{\text {Exp }}-\operatorname{mean}\left(\tau_{\text {Exp }}\right)\right)}\right]
$$

Where the norm function is given by the following equation: 


$$
\operatorname{Norm}(\mathrm{x}(\mathrm{i}))=\sqrt{\sum_{i=1}^{n} a b s\left(\mathrm{x}(\mathrm{i})^{2}\right)}
$$

According to each particular loading conditions such as magnetic field, frequency and strain, the fitness value is not calculated at a specific point $(x, y)$, but it is calculated based on the comparison between the experimental and model-predicted stress-strain curves (loops), containing thousands of $(x, y)$ points each.

Table 6. Fitness value of proposed model at training experimental data.

\begin{tabular}{|c|c|c|c|c|}
\hline \multicolumn{5}{|c|}{ Magnetic flux density $(0 \mathrm{mT})$} \\
\hline Freq. $(\mathrm{Hz})$ & $\gamma_{0}=2 \%$ & $\gamma_{0}=4 \%$ & $\gamma_{0}=8 \%$ & $\gamma_{0}=14 \%$ \\
\hline 0.5 & 84.21 & 85.81 & 85.85 & 85.33 \\
\hline 1 & 86.72 & 88.14 & 86.52 & 88.01 \\
\hline 3 & 84.23 & 89.71 & 90.35 & 89.62 \\
\hline 5 & 91.55 & 88.68 & 86.73 & 88.41 \\
\hline 8 & 95.35 & 89.47 & 94.46 & 87.18 \\
\hline \multicolumn{5}{|c|}{ Magnetic flux density (100 mT) } \\
\hline 0.5 & 86.14 & 87.97 & 88.22 & 87.48 \\
\hline 1 & 88.45 & 86.05 & 89.05 & 90.95 \\
\hline 3 & 89.58 & 89.51 & 93.66 & 86.28 \\
\hline 5 & 92.65 & 88.90 & 89.42 & 88.07 \\
\hline 8 & 86.79 & 91.02 & 92.23 & 86.41 \\
\hline \multicolumn{5}{|c|}{ Magnetic flux density (170 mT) } \\
\hline 0.5 & 87.60 & 86.39 & 87.13 & 86.85 \\
\hline 1 & 91.56 & 91.65 & 91.99 & 90.49 \\
\hline 3 & 96.04 & 92.35 & 89.11 & 87.18 \\
\hline 5 & 92.84 & 89.47 & 92.09 & 88.25 \\
\hline 8 & 89.71 & 89.01 & 90.43 & 85.85 \\
\hline \multicolumn{5}{|c|}{ Magnetic flux density (220 mT) } \\
\hline 0.5 & 85.21 & 93.49 & 88.82 & 83.20 \\
\hline 1 & 85.58 & 89.29 & 90.22 & 83.71 \\
\hline 3 & 90.77 & 88.21 & 91.63 & 84.45 \\
\hline 5 & 93.35 & 91.46 & 90.68 & 84.21 \\
\hline 8 & 88.01 & 89.94 & 88.87 & 82.82 \\
\hline \multicolumn{5}{|c|}{ Magnetic flux density $(260 \mathrm{mT})$} \\
\hline 0.5 & 95.02 & 90.46 & 86.99 & 80.38 \\
\hline 1 & 94.14 & 85.26 & 84.54 & 82.43 \\
\hline 3 & 90.72 & 89.36 & 88.75 & 81.66 \\
\hline 5 & 90.17 & 87.94 & 89.76 & 80.57 \\
\hline 8 & 88.68 & 86.32 & 87.29 & 78.79 \\
\hline
\end{tabular}

Table 7. Fitness value of proposed model extrapolating out of the training experimental data set range.

\begin{tabular}{lrrccc}
\hline \multicolumn{5}{c}{ Magnetic flux density $(0 \mathrm{mT})$} \\
\hline Freq. $(\mathrm{Hz})$ & $\gamma_{0}=1 \%$ & $\gamma_{0}=2 \%$ & $\gamma_{0}=4 \%$ & $\gamma_{0}=8 \%$ & $\gamma_{0}=14 \%$ \\
\hline 0.1 & 66.22 & 71.77 & 82.60 & 77.48 & 79.68
\end{tabular}


1

2

3

4

5

6

7

8

9

10

11

12

13

14

15

16

17

18

19

20

21

22

23

24

25

26

27

28

29

30

31

32

33

34

35

36

37

38

39

40

41

42

43

44

45

46

47

48

49

50

51

52

53

54

55

56

57

58

59

60

\begin{tabular}{|c|c|c|c|c|c|}
\hline 0.3 & 76.93 & 88.87 & 93.19 & 81.89 & 79.92 \\
\hline 0.5 & 71.56 & - & - & - & - \\
\hline 1 & 64.36 & - & - & - & - \\
\hline 3 & 77.00 & - & - & - & - \\
\hline 5 & 87.94 & - & - & - & - \\
\hline 8 & 91.23 & - & - & - & - \\
\hline \multicolumn{6}{|c|}{ Magnetic flux density $(100 \mathrm{mT})$} \\
\hline 0.1 & 66.65 & 78.05 & 78.06 & 75.40 & 71.62 \\
\hline 0.3 & 67.34 & 84.01 & 89.83 & 77.29 & 74.53 \\
\hline 0.5 & 72.41 & - & - & - & - \\
\hline 1 & 67.85 & - & - & - & - \\
\hline 3 & 77.31 & - & - & - & - \\
\hline 5 & 82.43 & - & - & - & - \\
\hline 8 & 76.37 & - & - & - & - \\
\hline \multicolumn{6}{|c|}{ Magnetic flux density $(170 \mathrm{mT})$} \\
\hline 0.1 & 77.31 & 78.30 & 78.83 & 85.82 & 84.68 \\
\hline 0.3 & 81.81 & 75.76 & 83.02 & 84.45 & 90.97 \\
\hline 0.5 & 74.98 & - & - & - & - \\
\hline 1 & 89.02 & - & - & - & - \\
\hline 3 & 87.51 & - & - & - & - \\
\hline 5 & 84.74 & - & - & - & - \\
\hline 8 & 69.73 & - & - & - & - \\
\hline \multicolumn{6}{|c|}{ Magnetic flux density $(220 \mathrm{mT})$} \\
\hline 0.1 & 78.03 & 84.34 & 89.12 & 90.65 & 80.27 \\
\hline 0.3 & 65.40 & 80.13 & 82.22 & 84.23 & 85.88 \\
\hline 0.5 & 74.58 & - & - & - & - \\
\hline 1 & 64.33 & - & - & - & - \\
\hline 3 & 78.15 & - & - & - & - \\
\hline 5 & 61.22 & - & - & - & - \\
\hline 8 & 73.24 & - & - & - & - \\
\hline \multicolumn{6}{|c|}{ Magnetic flux density $(260 \mathrm{mT})$} \\
\hline 0.1 & 68.92 & 91.36 & 77.14 & 76.67 & 78.27 \\
\hline 0.3 & 66.98 & 83.44 & 80.91 & 79.52 & 82.02 \\
\hline 0.5 & 72.27 & - & - & - & - \\
\hline 1 & 73.40 & - & - & - & - \\
\hline 3 & 75.70 & - & - & - & - \\
\hline 5 & 79.56 & - & - & - & - \\
\hline 8 & 75.21 & - & - & - & - \\
\hline
\end{tabular}

The fitness values are calculated and provided in Table 6. In most experimental cases, the fitness values are around $90 \%$ and the fitness values show that the proposed model can capture the dynamic behavior of the MRE quite well. The range of fitness values is from $78.79 \%$ to $96.04 \%$ and the average of the fitness value is $89.27 \%$. Based on the Table 6 , it is easy to see that when the loading conditions (frequency and displacement amplitude) and magnetic flux density reach the maximum value simultaneously, the performance of the proposed model decreases. Moreover, Table 7 shows that the proposed model can even extrapolate the dynamic behavior of MRE outside the range of training experimental data set and still achieve reasonable accuracy between $64.33 \%$ to $93.19 \%$, with the average of the fitness value is $79.11 \%$. 


\section{Conclusions}

In this study, we present a comprehensive model for the dynamic behavior of magnetorheological elastomers (MREs) under coupled tension-compression mode. We also present an experimental setup for measuring the relationships between stress and strain of MREs under different conditions (are plotted as hysteresis loops, used to fit model parameters, and later) to compare the results to further model predictions.

Observations include: The hysteresis behavior of the MREs is asymmetric in tension and in compression, and the asymmetry is enhanced with increase in the magnetic flux density, loading frequency, and displacement amplitude. Moreover, the enclosed area and the slope of major axis of the hysteresis loops depend on the magnetic flux density, motion frequency and displacement amplitude. Additionally, figures 4-6 document strain stiffening, strain-softening, and strain rate stiffening phenomena - a rich array of MRE behaviors, which are easy to identify in the plotted hysteresis loops.

The novel phenomenological model introduced here is able to describe this rich dynamic behavior of MREs with a single set of parameters fit to the training experimental data set using the leastsquares method. The model reproduces the nonlinear viscoelasticity and asymmetric hysteresis behavior as well as their magnitude and shape variations with changes in applied frequency, forcing amplitude and magnetic field. The effects of the model's parameters on the shape of the hysteresis loops are shown visually too.

The experimental results show that the proposed model can accurately capture the dynamic behavior of the MRE under tension-compression oscillation, over a wide range of magnetic flux density, loading frequency and strain. The experimental results show that the equivalent stiffness (dynamic storage modulus) and equivalent damping (elongational viscosity) are increased by incrementing the magnetic flux density and loading frequency. By increasing the displacement amplitude of excitation, the equivalent damping is increased while the equivalent stiffness is decreased. The results show that the proposed model is in accord with experimental data very well. 
Moreover, the model is capable of extrapolating predictions outside the range of the training experimental data set from which model's parameters are derived. We quantify the model's predictions to additional test experiments under the specified conditions. The use and further development of the phenomenological model presented here is would enable the design and control analysis of MRE devices under tension-compression cyclic loadings, taking advantage of their superior compactness and load-bearing capacities.

\section{References}

[1] Rabinow J 1948 The magnetic fluid clutch Electr. Eng. 2 1308-15

[2] Weber F 2014 Semi-active vibration absorber based on real-time controlled MR damper Mechanical Systems and Signal Processing 46 272-88

[3] Gu ZQ, Oyadiji SO 2008 Application of MR damper in structural control using ANFIS method Computers \& Structures 86 427-36

[4] Ghiotti A, Regazzo P, Bruschi S, Bariani PF 2010 Reduction of vibrations in blanking by MR dampers CIRP Annals - Manufacturing Technology 59 275-8

[5] Aly AM, Zasso A, Resta F 2011 On the dynamics of a very slender building under winds: response reduction using MR dampers with lever mechanism The Structural Design of Tall and Special Buildings 20 539-51 
[6] Yao HJ, Fu J, Yu M, Peng YX 2013 Semi-active control of seat suspension with MR damper $J$. Phys: Conf. Ser 412012054

[7] Dominguez A, Sedaghati R, Stiharu I 2008 Modeling and application of MR dampers in semiadaptive structures Computers \& Structures 86 407-15

[8] Mohajer Rahbari N, Farahmand Azar B, Talatahari S, Safari H 2013 Semi-active direct control method for seismic alleviation of structures using MR dampers Structural Control and Health Monitoring 20 1021-42

[9] Cha Y-J, Bai J-W 2016 Seismic fragility estimates of a moment-resisting frame building controlled by MR dampers using performance-based design Eng. Struct. 116 192-202

[10] Shrimali MK, Bharti SD, Dumne SM 2015 Seismic response analysis of coupled building involving MR damper and elastomeric base isolation Ain Shams Engineering Journal

[11] Vadtala IH, Soni DP, Panchal DG 2013 Semi-Active Control of a Benchmark Building using Neuro-Inverse Dynamics of MR Damper Proc. Eng. 51 45-54

[12] Li Z-X, Lv Y, Xu L-H, Ding Y, Zhao Q 2013 Experimental studies on nonlinear seismic control of a steel-concrete hybrid structure using MR dampers Eng. Struct. 49 248-63

[13] Kim GC, Kang JW 2011 Seismic Response Control of Adjacent Building by using Hybrid Control Algorithm of MR Damper Proc. Eng. 14 1013-20

[14] Bitaraf M, Ozbulut OE, Hurlebaus S, Barroso L 2010 Application of semi-active control strategies for seismic protection of buildings with MR dampers Eng. Struct. 32 3040-7

[15] Bharti SD, Dumne SM, Shrimali MK 2010 Seismic response analysis of adjacent buildings connected with MR dampers Eng. Struct. 32 2122-33

[16] Yang M-G, Chen Z-Q, Hua X-G 2011 An experimental study on using MR damper to mitigate longitudinal seismic response of a suspension bridge Soil Dynamics and Earthquake Engineering 31 1171-81

[17] Chen Z, Wang X, Ko J, Ni Y, Spencer B, Yang G, Hu J 2004 MR damping system for mitigating wind-rain induced vibration on Dongting Lake Cable-Stayed Bridge Wind and Structures 7 293-304

[18] Gordaninejad F, Saiidi M, Hansen BC, Chang F-K 1998 Control of bridges using magnetorheological fluid (MRF) dampers and a fiber-reinforced composite-material column Smart Systems for Bridges, Structures, and Highways, Proceedings of the 1998 SPIE Conf. on Smart Materials and Structures 3325 2-11

[19] Wang X, Gordaninejad F 2002 Lyapunov-Based Control of a Bridge Using MagnetoRheological Fluid Dampers J. Intell. Mater. Syst. Struct. 13 415-9 
[20] Weber F, Distl H 2015 Amplitude and frequency independent cable damping of Sutong Bridge and Russky Bridge by magnetorheological dampers Structural Control and Health Monitoring 22 $237-54$

[21] Zheng J, Li Y, Li Z, Wang J 2015 Transient multi-physics analysis of a magnetorheological shock absorber with the inverse Jiles-Atherton hysteresis model Smart Mater. Struct. 24105024

[22] Hu H, Jiang X, Wang J, Li Y 2012 Design, modeling, and controlling of a large-scale magnetorheological shock absorber under high impact load J. Intell. Mater. Syst. Struct. 23 635-45

[23] Nguyen Q-H, Choi S-B 2009 Optimal design of MR shock absorber and application to vehicle suspension Smart Mater. Struct. 18035012

[24] Guo HT, Liao WH 2012 A novel multifunctional rotary actuator with magnetorheological fluid Smart Mater. Struct. 21065012

[25] Yu J, Dong X, Wang W 2016 Prototype and test of a novel rotary magnetorheological damper based on helical flow Smart Mater. Struct. 25025006

[26] Cui J, Tan J, Wen X, Wen M, Yu M, Fu J, Wu Z 2015 Multi-functional hinge equipped with a magneto-rheological rotary damper for solar array deployment system 9446944648

[27] Moslått G-A, Myklebust E, Kolberg P, Karimi HR 2012 Modeling and control design for a semi-active suspension system with magnetorheological rotary brake ed: Proceedings of the 11th WSEAS international conference on Instrumentation, Measurement, Circuits and Systems, and Proceedings of the 12th WSEAS international conference on Robotics, Control and Manufacturing Technology, and Proceedings of the 12th WSEAS international conference on Multimedia Systems \& Signal Processing: World Scientific and Engineering Academy and Society (WSEAS)) 55-60 [28] Tran Hai N, Kyoung Kwan A 2009 A new structure of a magnetorheological brake with the waveform boundary of a rotary disk Smart Mater. Struct. 18115029

[29] Kavlicoglu BM, Gordaninejad F, Evrensel CA, Cobanoglu N, Liu Y, Fuchs A, Korol G 2002 High-torque magnetorheological fluid clutch ed: SPIE's 9th Annual International Symposium on Smart Structures and Materials: International Society for Optics and Photonics) 393-400 [30] Kavlicoglu BM, Gordaninejad F, Wang X 2013 Study of a magnetorheological grease clutch Smart Mater. Struct. 22125030

[31] Jonsdottir F, Gudmundsson FB, Gudmundsson KH, Lecomte C 2015 Preparation and Characterization of a Prototype Magnetorheological Elastomer for Application in Prosthetic Devices 7th ECCOMAS Thematic Conference on Smart Structures and Materials

[32] Du H, Li W, Zhang N 2011 Semi-active variable stiffness vibration control of vehicle seat suspension using an MR elastomer isolator Smart Mater. Struct. 20105003

[33] Sun S, Yang J, Deng H, Du H, Li W, Alici G, Nakano M 2015 Horizontal vibration reduction of a seat suspension using negative changing stiffness magnetorheological elastomer isolators Int. $J$. Veh. Des. 68 104-18 
[34] Bai X-X, Wereley NM 2014 Magnetorheological impact seat suspensions for ground vehicle crash mitigation ed: SPIE Smart Structures and Materials+ Nondestructive Evaluation and Health Monitoring: International Society for Optics and Photonics) 90570R-R-12

[35] Ladipo IL, Fadly JD, Faris WF 2016 Characterization of Magnetorheological Elastomer (MRE) Engine Mounts Materials Today: Proceedings 3 411-8

[36] Kavlicoglu B, Wallis B, Sahin H, Liu Y 2011 Magnetorheological elastomer mount for shock and vibration isolations Proc. SPIE 7977 79770Y

[37] Sethi MK, Kumar P, Kumar A 2016 Transient Vibration Reduction of a Powertrain Using MRE Based Adaptive Tuned Vibration Absorber Proc. Eng. 144 689-96

[38] Xu Z, Gong X, Liao G, Chen X 2010 An Active-damping-compensated Magnetorheological Elastomer Adaptive Tuned Vibration Absorber J. Intell. Mater. Syst. Struct. 21 1039-47

[39] Liao GJ, Gong XL, Kang CJ, Xuan SH 2011 The design of an active-adaptive tuned vibration absorber based on magnetorheological elastomer and its vibration attenuation performance Smart Mater. Struct. 20075015

[40] Sinko R, Karnes M, Koo J-H, Kim Y-K, Kim K-S 2011 Design and Test of an Adaptive Tuned Vibration Absorber for Reducing Cryogenic Cooler Vibrations ed: ASME 2011 Conference on Smart Materials, Adaptive Structures and Intelligent Systems: American Society of Mechanical Engineers) 325-31

[41] Sun S, Yang J, Li W, Deng H, Du H, Alici G 2015 Development of an MRE adaptive tuned vibration absorber with self-sensing capability Smart Mater. Struct. 24095012

[42] Sun S, Deng H, Yang J, Li W, Du H, Alici G, Nakano M 2015 An adaptive tuned vibration absorber based on multilayered MR elastomers Smart Mater. Struct. 24045045

[43] Deng H-x, Gong X-1, Wang L-h 2006 Development of an adaptive tuned vibration absorber with magnetorheological elastomer Smart Mater. Struct. 15 N111-N6

[44] Hoang N, Zhang N, Du H 2009 A dynamic absorber with a soft magnetorheological elastomer for powertrain vibration suppression Smart Mater. Struct. 18074009

[45] Komatsuzaki T, Inoue T, Iwata Y 2016 Experimental Investigation of an Adaptively Tuned Dynamic Absorber Incorporating Magnetorheological Elastomer with Self-Sensing Property ExM

[46] Behrooz M, Wang X, Gordaninejad F 2014 Performance of a new magnetorheological elastomer isolation system Smart Mater. Struct. 23045014

[47] Yang C, Fu J, Yu M, Zheng X, Ju B 2015 A new magnetorheological elastomer isolator in shear-compression mixed mode J. Intell. Mater. Syst. Struct. 26 1290-300 
[48] Kwietniewski M MD, Nguyen HP, Gieleta R, Osiński J. 2015 Numerical, experimental and analytical study on MRE used for vibrating pile hammer efficiency improvement Achievements in Materials and Manufacturing Engineering 73 151-6

[49] Bogdanov V, Borin D, Stepanov G, Andruszkiewicz A 2009 Usage of magneto-active elastomers in a bumper of a vehicle for front impact protection J. Phys. 149 1-4

[50] Farshad M, Le Roux M 2004 A new active noise abatement barrier system Polym. Test. 23 $855-60$

[51] Bose H, Rabindranath R, Ehrlich J 2012 Soft magnetorheological elastomers as new actuators for valves J. Intell. Mater. Syst. Struct. 23 989-94

[52] Lynch JP, Behrooz M, Yarra S, Mar D, Pinuelas N, Muzinich B, Publicover NG, Pekcan G, Itani A, Gordaninejad F 2016 A self-sensing magnetorheological elastomer-based adaptive bridge bearing with a wireless data monitoring system $\mathbf{9 8 0 3} 98030 \mathrm{D}$

[53] Park G, Chen S, Li R, Zhang Z, Wang X 2016 Multi-scale analysis and optimized design of laminated-MRE bearings 9799 97993M

[54] Lynch JP, Li R, Li X, Wu Y, Chen S, Wang X 2016 Analysis of longitudinal seismic response of bridge with magneto-rheological elastomeric bearings 9803 98034I

[55] Xing ZW, Yu M, Fu J, Wang Y, Zhao LJ 2015 A laminated magnetorheological elastomer bearing prototype for seismic mitigation of bridge superstructures J. Intell. Mater. Syst. Struct.

[56] Wang Y, Xuan S, Dong B, Xu F, Gong X 2016 Stimuli dependent impedance of conductive magnetorheological elastomers Smart Mater. Struct. 25025003

[57] Lee D, Lee M, Jung N, Yun M, Lee J, Thundat T, Jeon S 2014 Modulus-tunable magnetorheological elastomer microcantilevers Smart Mater. Struct. 23055017

[58] Maslowski M, Zaborski M 2015 Effect of thermooxidative and photooxidative ageing processes on mechanical properties of magnetorheological elastomer composites Polimery 60 264-71

[59] Aloui S, Klüppel M 2015 Magneto-rheological response of elastomer composites with hybridmagnetic fillers Smart Mater. Struct. 24025016

[60] Ni YQ, Ying ZG, Chen ZH 2010 Magneto-rheological elastomer (MRE) based composite structures for micro-vibration control Earthq. Eng. Eng. Vib. 9 345-56

[61] Lynch JP, Ghafoorianfar N, Gordaninejad F 2015 A magnetorheological elastomer compressive and shear sensor Proc. SPIE $943594351 \mathrm{E}$ 
[62] Bica I 2011 Magnetoresistor sensor with magnetorheological elastomers Journal of Industrial and Engineering Chemistry 17 83-9

[63] Li W, Kostidis K, Zhang X, Zhou Y 2009 Development of a force sensor working with MR elastomers ed: Advanced Intelligent Mechatronics, 2009. AIM 2009. IEEE/ASME International Conference on: IEEE) 233-8

[64] Wang X, Gordaninejad F, Calgar M, Liu Y, Sutrisno J, Fuchs A 2009 Sensing Behavior of Magnetorheological Elastomers J. Mech. Des. 131091004

[65] Liao W-H, Behrooz M, Gordaninejad F 2015 Behavior of a flexible controllable micropump Smart Structures and Materials 9431943109

[66] Behrooz M, Gordaninejad F 2016 A flexible micro fluid transport system featuring magnetorheological elastomer Smart Mater. Struct. 25025011

[67] Du G, Chen X 2012 MEMS magnetometer based on magnetorheological elastomer Measurement 45 54-8

[68] Behrooz M. A Controllable Flexible Micropump and a Semi-Active Vibration Absorber Using Magnetorheological Elastomers: UNIVERSITY OF NEVADA, RENO; 2015.

[69] Li Y, Li J, Li W, Du H 2014 A state-of-the-art review on magnetorheological elastomer devices Smart Mater. Struct. 23123001

[70] Deng YC, Bian YS, Gao ZH 2013 Study and Manufacture of Magneto-Rheological Vibration Absorber Based on Internal Resonance Appl. Mech Mater. 389 642-8

[71] Lynch JP, Li J, Li Y, Li W, Samali B, Yun C-B, Wang K-W 2013 Development of adaptive seismic isolators for ultimate seismic protection of civil structures Proc. SPIE $869286920 \mathrm{H}$

[72] Ginder JM, Nichols ME, Elie LD, Clark SM 2000 Controllable-stiffness components based on magnetorheological elastomers Proc. SPIE 3985 418-25

[73] Carlson JD, Jolly MR 2000 MR fluid, foam and elastomer devices Mechatronics 10 555-69

[74] Chen L, Gong XL, Li WH 2007 Microstructures and viscoelastic properties of anisotropic magnetorheological elastomers Smart Mater. Struct. 16 2645-50

[75] Popp KM, Kroger M, Li Wh, Zhang XZ, Kosasih PB 2009 MRE Properties under Shear and Squeeze Modes and Applications J. Intell. Mater. Syst. Struct. 21 1471-7

[76] Boczkowska A, Awietjan S. 2012 Microstructure and properties of magnetorheological elastomers. ed: Boczkowska A Advanced Elastomers-Technology, Properties and Applications (Warsaw, Poland: InTech) pp 147-80

[77] Ginder JM, Nichols ME, Elie LD, Tardiff JL 1999 Magnetorheological elastomers: properties and applications Proc. SPIE 3675 131-8 
[78] Ruddy C, Ahearne E, Byrne G 2012 A review of magnetorheological elastomers: properties and applications Adv. Manuf. Sci 20 1-7

[79] Ismail R, Ibrahim A, Hamid HA. 2014 A Review of Magnetorheological Elastomers: Characterization Properties for Seismic Protection. ed: Hassan R, Yusoff M, Ismail Z, Amin NM, Fadzil MA InCIEC 2013 (Singapore: Springer) pp 237-48

[80] Kaleta J, Kr?lewicz M, Lewandowski D 2011 Magnetomechanical properties of anisotropic and isotropic magnetorheological composites with thermoplastic elastomer matrices Smart Mater. Struct. 20085006

[81] Kallio M. 2005 The elastic and damping properties of magnetorheological elastomers (Finland: VTT publications) $\mathrm{p} 7$

[82] York D, Wang X, Gordaninejad F 2007 A New MR Fluid-Elastomer Vibration Isolator J. Intell. Mater. Syst. Struct. 18 1221-5

[83] Wang X, Gordaninejad F 2009 A new magnetorheological fluid-elastomer mount: phenomenological modeling and experimental study Smart Mater. Struct. 18095045

[84] Wang K-W, Wang X, Gordaninejad F, Hitchcock GH 2004 Dynamic behaviors of magnetorheological fluid-elastomer composites under oscillatory compression Proc. SPIE 5386 2508

[85] Zhu CS 2007 The response time of a magnetorheological fluid squeeze film damper rotor system ed: Key Eng. Mater.: Trans Tech Publ) 334 1085-8

[86] Sahin H, Gordaninejad F, Wang X, Liu Y 2012 Response time of magnetorheological fluids and magnetorheological valves under various flow conditions J. Intell. Mater. Syst. Struct. 23 949-57

[87] Laun H, Gabriel C 2007 Measurement modes of the response time of a magneto-rheological fluid (MRF) for changing magnetic flux density Rheol. Acta 46 665-76

[88] Spaggiari A 2012 Properties and applications of Magnetorheological fluids Fracture and Structural Integrity 48-61

[89] Ubaidillah, Sutrisno J, Purwanto A, Mazlan SA 2015 Recent Progress on Magnetorheological Solids: Materials, Fabrication, Testing, and Applications Adv. Eng. Mater. 17 563-97

[90] Bazinenkov AM, Mikhailov VP 2015 Active and Semi Active Vibration Isolation Systems Based on Magnetorheological Materials Proc. Eng. 106 170-4

[91] Schubert G, Harrison P 2015 Large-strain behaviour of Magneto-Rheological Elastomers tested under uniaxial compression and tension, and pure shear deformations Polym. Test. 42 122-34

[92] Liao G, Gong X, Xuan S, Guo C, Zong L 2012 Magnetic-Field-Induced Normal Force of Magnetorheological Elastomer under Compression Status Ind. Eng. Chem. Res. 51 3322-8

[93] Guan X, Dong X, Ou J 2008 Magnetostrictive effect of magnetorheological elastomer Journal of Magnetism and Magnetic Materials 320 158-63 
[94] Ginder JM, Schlotter WF, Nichols ME 2001 Magnetorheological elastomers in tunable vibration absorbers Proc. SPIE 4331 103-10

[95] Albanese A-M, Cunefare KA 2003 Properties of a magnetorheological semi-active vibration absorber Proc. SPIE 5052 36-43

[96] Yao Z, Fang J, Chen JC, Wang W 2003 Investigation of hard magnetic silicone elastomer thin films Proc. SPIE 4982 120-9

[97] Zhou GY, Wang Q 2005 Magnetorheological elastomer-based smart sandwich beams with nonconductive skins Smart Mater. Struct. 14 1001-9

[98] Zhou GY, Wang Q 2005 A linear time-variant system for signal modulation by use of magnetorheological elastomer-suspended beams Smart Mater. Struct. 14 1154-62

[99] Wang K-W, Wang X, Gordaninejad F, Hitchcock G 2005 A magneto-rheological fluidelastomer vibration isolator Proc. SPIE 5760 217-25

[100] Zhou GY, Wang Q 2005 Field-dependent dynamic properties of magnetorheological elastomerbased sandwich beams Proc. SPIE 5760 226-37

[101] Flatau AB, Zhou GY, Wang Q 2005 Use of magnetorheological elastomer for smart piezoelectric power actuator design and signal processing Proc. SPIE 5764 411-20

[102] Zhou GY, Wang Q 2006 Use of magnetorheological elastomer in an adaptive sandwich beam with conductive skins. Part I: Magnetoelastic loads in conductive skins Int. J. Solid. Struct. 43 5386402

[103] Zhou GY, Wang Q 2006 Use of magnetorheological elastomer in an adaptive sandwich beam with conductive skins. Part II: Dynamic properties Int. J. Solid. Struct. 43 5403-20

[104] Zhou GY, Wang Q 2006 Study on the adjustable rigidity of magnetorheological-elastomerbased sandwich beams Smart Mater. Struct. 15 59-74

[105] Zhou GY, Lin KC, Wang Q 2006 Finite element studies on field-dependent rigidities of sandwich beams with magnetorheological elastomer cores Smart Mater. Struct. 15 787-91

[106] Gong XL, Zhang XZ, Zhang PQ 2005 Fabrication and characterization of isotropic magnetorheological elastomers Polym. Test. 24 669-76

[107] Zhou GY 2004 Complex shear modulus of a magnetorheological elastomer Smart Mater. Struct. 13 1203-10

[108] Wen Y-K 1976 Method for random vibration of hysteretic systems J. Eng. Mech. Div. 102 249-63 
[109] Y. Yu YLaJL 2014 A New Hysteretic Model for Magnetorheological Elastomer Base Isolator and Parameter Identification Based on Modified Artificial Fish Swarm Algorithm Proceedings of the 31st ISARC 176-83

[110] Behrooz M, Wang X, Gordaninejad F 2014 Modeling of a new semi-active/passive magnetorheological elastomer isolator Smart Mater. Struct. 23045013

[111] Li Y, Li J 2013 Development and Modeling of a Highly-Adjustable Base Isolator Utilizing Magnetorheological Elastomer ASME 2013 Conference on Smart Materials, Adaptive Structures and Intelligent Systems V001T03A10

[112] Yu Y, Li Y, Li J 2014 A Novel Strain Stiffening Model for Magnetorheological Elastomer Base Isolator and Parameter Estimation Using Improved Particle Swarm Optimization ed: Rodellar J, Guemes A, Pozo F 6th World Conference on Structural Control and Monitoring (Barcelona, Spain: IASCM) 1318

[113] Yang J, Du H, Li W, Li Y, Li J, Sun S, Deng H 2013 Experimental study and modeling of a novel magnetorheological elastomer isolator Smart Mater. Struct. 22117001

[114] Zhou GY 2003 Shear properties of a magnetorheological elastomer Smart Mater. Struct. 12 139

[115] Opie S, Yim W 2010 Design and Control of a Real-Time Variable Modulus Vibration Isolator J. Intell. Mater. Syst. Struct. 22 113-25

[116] Collette C, Kroll G, Saive G, Guillemier V, Avraam M, Preumont A 2009 Isolation and damping properties of magnetorheologic elastomers J. Phys: Conf. Ser 149012091

[117] Kallio M, Lindroos T, Aalto S, Järvinen E, Kärnä T, Meinander T 2007 Dynamic compression testing of a tunable spring element consisting of a magnetorheological elastomer Smart Mater. Struct. 16 506-14

[118] Liao G, Gong X, Xuan S 2013 Magnetic Field-Induced Compressive Property of Magnetorheological Elastomer under High Strain Rate Ind. Eng. Chem. Res. 52 8445-53

[119] Koo J-H, Khan F, Jang D-D, Jung H-J 2010 Dynamic characterization and modeling of magneto-rheological elastomers under compressive loadings Smart Mater. Struct. 19117002

[120] Bellan C, Bossis G 2002 Field dependence of viscoelastic properties of MR elastomers Int. J. Mod Phys B 16 2447-53

[121] Schubert G, Harrison P 2016 Equi-biaxial tension tests on magneto-rheological elastomers Smart Mater. Struct. 25015015

[122] Kallio M, Lindroos T, Aalto S, rvinen EJ, rn TK, Meinander T 2007 Dynamic compression testing of a tunable spring element consisting of a magnetorheological elastomer Smart Mater. Struct. 16506 
[123] Zhou GY, Li JR 2003 Dynamic behavior of a magnetorheological elastomer under uniaxial deformation: I. Experiment Smart Mater. Struct. 12859

[124] Li WH, Zhou Y, Tian TF 2010 Viscoelastic properties of MR elastomers under harmonic loading Rheol. Acta 49 733-40

[125] Zhu J-T, Xu Z-D, Guo Y-Q 2012 Magnetoviscoelasticity parametric model of an MR elastomer vibration mitigation device Smart Mater. Struct. 21075034

[126] Eem S-H, Jung H-J, Koo J-H 2012 Modeling of magneto-rheological elastomers for harmonic shear deformation IEEE Trans. Magn. 48 3080-3

[127] Yang J, Du H, Li W, Li Y, Li J, Sun S, Deng HX 2013 Experimental study and modeling of a novel magnetorheological elastomer isolator Smart Mater. Struct. 22117001

[128] Diani J, Fayolle B, Gilormini P 2009 A review on the Mullins effect Eur. Polym. J. 45 601-12

[129] Hu W, Wereley NM, Bell RC, Zimmerman DT, Govindarajan B, Shapiro B, Zinn B. 2012 Anelastic Behavior in Filled Elastomers Under Harmonic Loading Using Distributed Rate-Dependent Elasto-Slide Elements (INTECH Open Access Publisher) p

[130] Brown R. 2006 Physical testing of rubber (Springer US: Springer Science \& Business Media) $\mathrm{p}$

[131] Li Y, Li J, Li W, Samali B 2013 Development and characterization of a magnetorheological elastomer based adaptive seismic isolator Smart Mater. Struct. 22035005

[132] Molchanov VS, Stepanov GV, Vasiliev VG, Kramarenko EY, Khokhlov AR, Xu Z-D, Guo YQ 2014 Viscoelastic Properties of Magnetorheological Elastomers for Damping Applications Macromolecular Materials and Engineering 299 1116-25

[133] Xu ZD, Huang XH, Lu LH 2011 Experimental study on horizontal performance of multidimensional earthquake isolation and mitigation devices for long-span reticulated structures $J V C \mathbf{1 8}$ 941-52

[134] Xu ZD, Xu C, Hu J 2013 Equivalent fractional Kelvin model and experimental study on viscoelastic damper JVC 21 2536-52

[135] W.P. Fletcher ANG 1953 Non-linearity in the dynamic properties of vulcanised rubber compounds Transactions of the Institution of the Rubber 29 266-80

[136] Payne AR, Whittaker RE 1971 Low Strain Dynamic Properties of Filled Rubbers Rubber Chem. Technol. 44 440-78

[137] Leblanc JL 2002 Rubber-filler interactions and rheological properties in filled compounds Prog. Polym. Sci. 27 627-87 
[138] Payne AR 1962 The dynamic properties of carbon black-loaded natural rubber vulcanizates. Part I J. Appl. Polym. Sci. 6 57-63

[139] Rendek M, Lion A 2010 Amplitude dependence of filler-reinforced rubber: Experiments, constitutive modelling and FEM - Implementation Int. J. Solid. Struct. 47 2918-36

[140] Sorokin VV, Ecker E, Stepanov GV, Shamonin M, Monkman GJ, Kramarenko EY, Khokhlov AR 2014 Experimental study of the magnetic field enhanced Payne effect in magnetorheological elastomers Soft Matter 10 8765-76

[141] An H, Picken SJ, Mendes E 2012 Nonlinear rheological study of magneto responsive soft gels Polymer 53 4164-70

[142] Lion A, Retka J, Rendek M 2009 On the calculation of predeformation-dependent dynamic modulus tensors in finite nonlinear viscoelasticity Mechanics Research Communications 36 653-8

[143] Fuchs A, Zhang Q, Elkins J, Gordaninejad F, Evrensel C 2007 Development and characterization of magnetorheological elastomers J. Appl. Polym. Sci. 105 2497-508

[144] Yang J, Gong X, Deng H, Qin L, Xuan S 2012 Investigation on the mechanism of damping behavior of magnetorheological elastomers Smart Mater. Struct. 21125015

[145] Yanceng F, Xinglong G, Shouhu X, Wei Z, Jian Z, Wanquan J 2011 Interfacial friction damping properties in magnetorheological elastomers Smart Mater. Struct. 20035007

[146] Li W, Sun L, Sun J, Chen W, Ma F, Leng D 2013 Experimental and numerical investigation on damping properties and energy dissipation mechanisms of magnetosensitive rubber J. Phys: Conf. Ser 412012030

[147] Shuib RK, Pickering KL, Mace BR 2015 Dynamic properties of magnetorheological elastomers based on iron sand and natural rubber J. Appl. Polym. Sci. 13241506

[148] Hegde S, Kiran K, Gangadharan KV 2015 A novel approach to investigate effect of magnetic field on dynamic properties of natural rubber based isotropic thick magnetorheological elastomers in shear mode Journal of Central South University 22 2612-9 